\title{
EN TORNO A LA DEFINICIÓN DE LOS TÉRMINOS GRAMATICALES EN LAS EDICIONES DEL DRAE DE 1817 A 1852
}

\section{ON THE DEFINITION OF GRAMMATICAL TERMS IN THE DICTIONARY OF THE SPANISH ACADEMY SINCE 1817 UNTIL 1852}

\author{
María Antonia Martínez Linares \\ Universidad de Alicante \\ antonia.martinez@ua.es
}

Recibido: $27 / 12 / 2018$

Aceptado: 14/02/2019

\begin{abstract}
Resumen
Este trabajo muestra que el tratamiento de los términos gramaticales en el Diccionario de la Academia desde la sexta edición de 1822 hasta la undécima de 1852 está presidido por el continuismo y la convergencia con la propia tradición académica representada por las anteriores ediciones del Diccionario y por la Gramática, particularmente por la edición de 1796 , cuyo planteamiento no se vería modificado hasta la tímida reforma de 1854 .

Está basado en el examen de 177 definiciones de términos gramaticales en las ediciones objeto de estudio y se ha prestado especial atención al tratamiento de los términos alusivos a las nociones teóricamente más relevantes en las gramáticas españolas de la primera mitad del siglo XIX: las referidas a las "partes de la oración" y sus particularidades, objeto de la Analogía, y a la sintaxis.

PALABRAS CLAVE: términos gramaticales, Diccionario académico, Gramática académica, "partes de la oración”, sintaxis.
\end{abstract}

\begin{abstract}
This work shows that the treatment of grammatical terms in the Dictionary of the Spanish Academy since the sixth edition published in 1822 until the eleventh of 1852 is dominated by continuity and convergence with its own academic tradition. This tradition is represented by the previous editions of the Dictionary and by the Grammar, particularly by the fourth edition published in 1796, whose grammatical approach would not be modified until the timid reform of 1854 .

The work is based on the examination of 177 definitions of grammatical terms in the Dictionary editions under study. Special attention has been paid to the definition of the terms which refer to the most relevant notions in Spanish grammars of the first half of the XIX century; that is, the definitions that refer to "parts of speech" and their peculiarities, the object of Analogy, and those that refer to syntax.

KEYWORDS: grammatical terms, Dictionary of Royal Spanish Academy, Grammar of Royal Spanish Academy, "parts of speech", syntax.
\end{abstract}

Para citar este artículo / To cite this article: Martínez Linares, María Antonia. (2019). En torno a la definición de las palabras gramaticales en las ediciones del DRAE de 1817 a 1852. Azorín, Dolores; Clavería, Gloria y Jiménez Ríos, Enrique (Eds.): ELUA: El diccionario de la Academia y su tiempo: lexicografia, lengua y sociedad en la primera mitad del siglo XIX, Anexo V, págs. 285-314.

Enlace/Link: http://dx.doi.org/10.14198/ELUA2019.ANEXO5.12 


\section{EL “CLIMA" GRAMATICAL DE LA PRIMERA MITAD DEL XIX Y LAS GRA- MÁTICAS DE LA ACADEMIA}

La primera mitad del XIX -el periodo en el que se inscriben los diccionarios objeto de estudio- representa una etapa de sumo interés para el desarrollo de la gramática. Según Gómez Asencio (2008: 39), en este espacio de tiempo se habían publicado más de treinta textos de gramática y se habían ido introduciendo "muchas novedades en la gramaticografía del español". A este periodo corresponde, en efecto, la difusión de la gramática general o filosófica, a la que se deben aspectos sumamente relevantes en la evolución de la gramática; entre ellos: la identificación de la oración, y no de la palabra, como unidad central; la adopción de la oración -o de la proposición- como marco para la delimitación y descripción de las clases de palabras (Gómez Asencio 1981: 353); la difusión del análisis lógico y gramatical, que llevaba a la descomposición del razonamiento en periodos, de estos en proposiciones y estas a su vez en sujetos, atributos, con diferentes formas de complejidad (Calero 2008: 12); la incorporación de otras nociones funcionales, como el concepto sintáctico-semántico de complemento (Gómez Asencio 1981: 61), o la identificación de unidades complejas, como la frase, intermedias entre la oración y la palabra, cuestiones clave para percibir "los diversos niveles jerarquizados" (Calero 2008: 12) de la oración y la estructura de las oraciones complejas (Gómez Asencio 1987: 118; Martínez Linares 2006). A ella se deben, asimismo, otros planteamientos que, de conformidad con Gómez Asencio (1981) y Calero (1986), representarían la modernidad en esta etapa, tales como la separación de sustantivo y adjetivo como categorías léxicas distintas y no como subclases del nombre, el tratamiento del pronombre como término deíctico o como elemento designativo de las personas del discurso, la caracterización del artículo definido a partir de la noción de determinación como procedimiento para dirigir hacia la realidad los signos y su inclusión en la categoría más amplia de los determinantes o determinativos, o la definición del adverbio como parte de la oración que modifica no solo al verbo, sino también al adjetivo o a otro adverbio.

Es preciso destacar, por último, que este es también el periodo en el que se publican las dos gramáticas que, según reconoce la Academia en el prólogo de la Gramática de 1854, impulsarían los cambios, las novedades incorporadas en esta edición ${ }^{1}$ : la Gramática de la lengua castellana según ahora se habla, de Vicente Salvá, cuya primera edición es de 1830, y la Gramática de la lengua castellana destinada al uso de los americanos de Andrés Bello - publicada por primera vez en 1847- que entroncaría con la gramática filosófica en muchos aspectos y que, con respecto a la tradición gramatical renacentista, suponía un enfoque gramatical realmente nuevo.

No obstante, la gramática académica de la primera mitad del XIX no experimentaría cambios notables. Hasta la quinta edición de 1854, la primera de este periodo realmente "nueva"2 (Gómez Asencio 2008: 40; Garrido Vílchez 2007: 362), el modelo de gramática

1 Aunque en realidad, como han destacado diversos investigadores, las innovaciones no fueron finalmente tantas como cabría esperar. Según Garrido Vílchez, por ejemplo, "el influjo de estos gramáticos es mucho menor de lo que presume la GRAE-1854" (2008: 211); así, hasta la edición de 1870 no se encuentra en la gramática académica una "asunción de principios doctrinales semejantes a los del valenciano" (2008: 223). Igualmente desde el punto de vista de Rojo (2001: 35) las gramáticas de Salvá y de Bello "no tienen sobre el texto académico la incidencia que cabría esperar por la importancia que poseen en la historia de la Gramática española".

2 "Respetuosa" en cualquier caso con la anterior. Además, de conformidad con Hernando García-Cervigón (2002:202), esta edición de 1854 marcaría el inicio de una cierta preocupación por la reforma de la "doctrina 
académica vigente seguiría siendo el de la edición de 1796, el mismo que estaba en vigor cuando se publicó la quinta edición del Diccionario en 1817 (Blanco 2018). Por tanto, pese a existir un "clima" gramatical innovador, que dio lugar a que "por doquier" se reclamara "doctrina nueva" en esta materia a la Academia (Gómez Asencio 2008: 39), en el quehacer académico de este periodo se pondría de manifiesto el inmovilismo, la lentitud a la hora de abordar reformas, que comúnmente han atribuido a la Academia los historiadores de nuestra gramática y que se ha venido vinculando a diversos motivos entre los que destacan:

a) La prioridad dada por la Academia a las tareas relacionadas con la mejora del diccionario -el proyecto principal $^{3}$ - en detrimento de las que pudiera requerir la gramática (Bosque 2013: 237; Garrido Vílchez 2008: 123 y sigs.; Gómez Asencio 2008: 37).

b) La preeminencia otorgada al carácter pedagógico, a la orientación didáctico-normativa, sobre las cuestiones de índole teórica, que justificaba el mantenimiento de un modelo de gramática basado en la tradición grecolatina y avalado por su difusión en la enseñanza (Garrido Vílchez 2009: 158; Bosque 2013: 239); a ello ha de añadirse la equidistancia que, a juicio de la Academia, debía mantener una "corporación oficial" en relación con las diferentes doctrinas gramaticales y su resistencia a "dejarse impresionar por novedades clasificatorias, terminológicas" (Garrido Vílchez 2008: 247) o, simplemente, a dar cabida a innovaciones que no estuvieran plenamente asentadas ${ }^{4}$.

c) El peso que, de cara a frenar reformas profundas, tenía el respeto a la propia tradición de la Academia y la necesidad subsiguiente de mantener cierta continuidad tanto con las gramáticas anteriores como con el diccionario ${ }^{5}$, partes, al fin y al cabo, de una misma obra académica ${ }^{6}$.

d) A todo eso debe sumarse por último, como sugieren Bosque (2013: 239) y Garrido Vílchez (2009: 136), la "naturaleza siempre polémica de las cuestiones sometidas a debate" en las comisiones y la "falta de conciliación de puntos de vista" entre sus integrantes.

Así pues, si se tiene en cuenta que tanto la decisión de considerar "gramaticales" determinadas entradas léxicas como la definición que se les asocie suponen una manera de "concebir la gramática y sus elementos" (Val Álvaro 1992: 7), si la manera en que la Academia concibe la gramática y sus elementos no cambia en este periodo, si el diccionario, por su condición de parte de la "obra" académica, ha de ser coherente tanto con las anteriores ediciones como con las gramáticas, es lógico plantearse si el tratamiento de los términos gramaticales en las diferentes ediciones del $D R A E^{7}$ de la primera mitad del siglo XIX, incluida la décima edición de 1852, podría desviarse de esa línea de fidelidad a la propia tradición. Cabe pues preguntarse si los diccionarios de este periodo introducirían cambios destacables

\footnotetext{
gramatical".

3 Al fin y al cabo, en palabras de Azorín Fernández (2004: 161) "la necesidad de elaborar el diccionario constituye el impulso inicial que provoca la fundación de la Academia”.

4 Véase también Gómez Asencio 2002-2004: 479-481.

5 Como indica Ruhstaller (2003: 237) el DRAE siempre ha respetado "una larga tradición que lo marca profundamente".

6 De ahí que, por ejemplo, según recogen las actas académicas del 22-VII-1847 (Sarmiento 1979: 79), se acordara recomendar a los académicos que habían de elaborar la nueva gramática de 1854 que, aunque introdujeran mejoras, procurasen "separarse lo menos posible del plan y método de ediciones anteriores" y que en el tratamiento de las "partes de la oración" procurasen asimismo guardar conformidad con los artículos correspondientes del Diccionario "en cuanto sea dable".

7 Diccionario de la Real Academia Española.
} 
respecto a la edición de $1817^{8}$ en lo que atañe a los términos gramaticales, si reflejarían en mayor o menor medida algunas de las innovaciones que se iban produciendo en el panorama gramatical español, o si se ceñirían a la "doctrina" de las gramáticas académicas en cuestiones relevantes, tales como las que tienen que ver con las "partes de la oración" -la columna vertebral de la gramática académica del XIX- o con la sintaxis.

Este trabajo tiene por objeto responder a esas preguntas y para ello se han examinado y comparado las definiciones de 177 unidades léxicas (véase Apéndice ${ }^{9}$ ) relacionadas con el metalenguaje de la gramática ${ }^{10}$ en las diferentes ediciones del Diccionario desde la quinta, de 1817, hasta la undécima de 1852. Ocasionalmente también se han consultado otras ediciones anteriores y posteriores a las del periodo acotado, como la de 1869 , posterior a la GRAE de 1854, y la de 1884, más innovadora en cuestiones gramaticales.

Para elaborar el corpus de definiciones se han utilizado las copias digitales de los diccionarios accesibles a través de Google Books. Las 177 unidades léxicas examinadas se han seleccionado teniendo en cuenta, en primer lugar, el hecho de que presentaran acepciones con la marca técnica Gram. ${ }^{11}$ en alguna de las ediciones del Diccionario del periodo examinado; es, por ejemplo, el caso de acento o de aspirar, que figuran con acepciones marcadas como Gram. en las diferentes ediciones del DRAE objeto de este estudio; es también el caso, por poner otros ejemplos, de apódosis, que incorpora marca de especialidad en la edición de 1852 aunque no en las anteriores, o de colon, registrado como Gram. en 1817 y sin marca técnica en las ediciones posteriores. Se han incluido asimismo en el conjunto de términos analizados otras voces que no aparecen con marca técnica pero cuya definición sí las adscribe a la gramática; así ocurre, por ejemplo, con aféresis, definida en algunas de estas ediciones como "figura gramatical" aunque no presente marca de especialidad, o con figura, cuya definición incluye, en todas las ediciones de 1817 a 1852, la acotación "entre gramáticos, retóricos y poetas", o con el término ordinal, que se describe asimismo en esas ediciones como "adjetivo que se aplica en la gramática á los nombres que señalan el orden de las cosas, y el lugar en que se han de colocar". Por último, se han considerado como objeto de examen otros términos carentes de marca técnica pero pertenecientes al ámbito de la gramática según el uso que se hace de ellos en las GRAEs y en otros textos gramaticales del periodo objeto de estudio. Así ocurre, por ejemplo, con accidente, desinencia, demostrativo, complemento, proposición, sustantivo o sujeto. Para la selección de esos términos no marcados se han tomado como referencia las gramáticas académicas del periodo considerado junto con la información que ha venido proporcionando la bibliografía especializada sobre las gramáticas españolas en esta etapa y los datos que aportan los trabajos específicos sobre términos gramaticales ${ }^{12}$ en las obras de la Academia; entre ellos,

8 Edición en la que, de conformidad con Blanco (2018), estaban ya bien representados los términos gramaticales.

9 En un apéndice se indica cuáles son esas unidades léxicas; se indica, además, cuáles presentaban acepciones con marca Gram. en todas o en alguna de las ediciones examinadas; cuáles figuraban con otra marca de especialidad; cuáles no presentaban marca técnica pero su pertenencia a la gramática se indicaba en la definición o se podía inferir de ella; cuáles carecían de marca y no incluían acepciones propias de la gramática.

10 Como afirma Val Álvaro (1992: 8), esa clase de términos constituyen una fuente importante, aunque no única, de acceso al modelo - o a los modelos- de gramática que se toman como referencia para su definición.

11 Evidentemente, el hecho de que los diccionarios estén digitalizados ha facilitado la búsqueda de unidades con esa marca de especialidad.

12 Sobre la evolución del Diccionario en líneas generales pueden verse, por ejemplo, los trabajos de Alvar Ezquerra $(1983,1993)$ referidos al $D R A E$ y sus prólogos. 
el estudio de Val Álvaro (1992) sobre las ideas gramaticales en el Diccionario de Autoridades, el trabajo de Blanco (2018) sobre la terminología de los términos de la ortografía y la gramática en el DRAE de 1817 y el estudio de Gaviño (2015) sobre la terminología gramatical de la Academia.

\section{ADICIONES Y CAMBIOS DE MARCA}

En las ediciones de este periodo sí se van incorporando algunos términos o sentidos gramaticales (y marcados como tales) inexistentes en la quinta edición; pero, a juzgar al menos por las incorporaciones que se han constatado ${ }^{13}$, no atañen a cuestiones nucleares ni refieren a conceptos realmente novedosos en el panorama gramatical; tampoco reflejan en todos los casos una noción clara que permita inferir su relevancia en la gramática.

Así, por ejemplo, a partir de 1832 se incluye en la entrada de propiedad la acepción, marcada como Gram., "La significacion ó sentido peculiar y exacto de una voz ó expresión"; en la entrada de inciso se agrega al concepto ortográfico existente hasta 1817 una nueva acepción, conceptuada igualmente como Gram., que remite a la noción de periodo -"El sentido parcial de un período que se anuncia en pocas palabras"-, si bien se da el caso de que periodo aún no aparece en esta edición marcado como término gramatical o con alguna otra marca técnica. Se incorpora una nueva entrada para prepositivo, con una definición, señalada como Gram., que lo presenta como término equivalente a "antepuesto"14. Ya en la edición de 1852 se añadiría en el suplemento, además de casos oblicuos ${ }^{15}$ - “todos los del nombre á excepción del nominativo"-, el lema prepositivos, con una definición referida a nombres y verbos formados con "preposiciones" en el sentido amplio -que abarca a prefijos - con que usaba la Academia el término: "Se aplica á los nombres y verbos compuestos de una ó mas preposiciones y un verbo ó un nombre; como subteniente, independencia, reedificar, descomponer".

La novena edición de 1843 agregaría en la entrada de elidir una acepción señalada como gramatical ${ }^{16}$, con un sentido que se mantendrá en las diferentes ediciones del XIX e incluso del XX: "Suprimir la vocal con que acaba una palabra, cuando la que sigue empieza con otra vocal, como del por de el, al por á el".

En cuanto a la edición de 1852, aparte de las voces antes mencionadas como incorporaciones del suplemento, registra, por ejemplo, la inclusión del término apódosis entre las voces marcadas como gramaticales, aunque ni el concepto resulta enteramente comprensible ni tampoco, al parecer, resulta clara su inclusión como término de la gramática. Así, mientras apódosis se cataloga como Gram. y se define como "segundo miembro de la oración, en el cual va á terminarse y completarse el sentido de ella", su complementario, prótasis, se relaciona con "periodo compuesto" y no con "oración", y sigue figurando, al igual que en ediciones anteriores, como voz de la retórica, no de la gramática: "Ret. En

13 Con la marca Gram. se incorporan propiedad, inciso, casos oblicuos, prepositivo, prepositivos, elidir. Con la catalogación de "figura" gramatical se incluiría aféresis en la edición de 1832.

14 PREPOSITIVO. adj. Gram. Antepuesto, lo que sirve para estar puesto antes ó en el principio de una voz etc. Praepositivus.

15 Sin embargo, no figura caso recto en el diccionario.

16 Así se usa, por ejemplo, en la gramática de Salvá, cuando habla de que "se elide la e del artículo masculino, siempre que lo preceden las preposiciones de ó á, diciéndose ahora generalmente del y al" (1835: 151), aunque no figura este sentido en el diccionario de Salvá. 
el período compuesto la primera parte de él hasta donde empieza a descender el sentido". Es de destacar en cualquier caso que, a partir de la edición de $1869^{17}$, apódosis, ya definida como parte de un periodo, también dejaría de figurar como voz gramatical para ser catalogada como término del campo de la retórica.

Ahora bien, aunque se registran en las ediciones de este periodo adiciones gramaticales como las señaladas, también se podría destacar alguna ausencia reseñable en cuestiones de gramática, dejando de momento al margen las ausencias en materia sintáctica. Así por ejemplo, pese a su utilización como términos técnicos en las diferentes ediciones de la $G R A E^{18}$, los diccionarios no incluirían hasta la edición de 1869 el sentido gramatical de accidente -el término con el que se alude en las GRAE a la flexión de las clases de palabras "declinables"19-, o el de antecedente, "la persona o cosa ya dicha" a la que se refieren los relativos (GRAE 1796: 81), o el de gentilicio, como clase de "nombre" que denota "la gente, nación ó patria de cada uno" (GRAE 1796: 34); tampoco incorporaría acepciones técnicas que se marquen como gramaticales para personal y para demostrativo aun cuando figuren en el diccionario, al igual que en las gramáticas, como clases de pronombres; hasta la edición de 1884 no se incluiría numeral como clase de adjetivo, o el concepto gramatical de desinencia ${ }^{20}$, aunque en la GRAE de 1854 se hablara de "desinencias" del verbo y de "partes de la oración" que se catalogan como "variables en sus desinencias".

En cuanto a términos asociados a otras formas de hacer gramática que podrían haber figurado en el Diccionario, es de destacar, por ejemplo, que hasta 1884 no se daría entrada a los conceptos de "gramática general" y de "gramática particular" que, si bien no existían como distinción metodológica explícita en la gramática académica de la primera mitad del XIX, sí correspondían a una distinción generalizada en otros textos gramaticales de este periodo (Garrido Vílchez 2008: 225; Gómez Asencio 1981: 23 y sigs.).

No parecen tener cabida asimismo otros conceptos extendidos a partir de otros modelos gramaticales o vinculados a otras maneras de concebir las categorías, como la extensión del concepto de artículo para incluir el indefinido un o el resto de los determinantes (Gómez Asencio 1981: 159), o los sentidos "técnicos" asociados al ámbito de la determinación como procedimiento para fijar la extensión y orientar la referencia de los sustantivos. Así en la edición de 1852 ni determinar ${ }^{21}$ ni determinativo ${ }^{22}$ incluyen algún sentido gramatical y la acepción especializada que sí incorpora determinante se refiere exclusivamente al verbo, como hacía Autoridades: “p. a. de determinar. El que ó lo que determina. || m. Gram. El verbo que en la oración determina á otro para que se coloque en distinto modo y tiempo. Verbum determinans".

17 En el DRAE de 1992 se marcaría como gramatical el sentido de apódosis como miembro de una oración condicional.

18 Gramática de la Real Academia Española.

19 Ni la GRAE de 1796 ni la de 1854 ofrecen una definición de accidente, pero utilizan el término para aludir a las variaciones de género, número y declinación de sustantivos, adjetivos, artículos y participios, así como variaciones formales propias de la conjugación de los verbos.

20 En las ediciones de este periodo desinencia se marca como término de la retórica y se define de esta manera: "El modo de acabar o terminar alguna palabra o alguna cláusula".

21 DETERMINAR. a. Resolver lo que se ha de hacer en alguna cosa. Úsase también como recíproco. Decernere, consilium capere. || Distinguir, discernir alguna cosa. Discernere. || Señalar, fijar alguna cosa para algún efecto; como determinar dia, hora etc. Decernere, constituere. $\backslash \backslash$ Resolver la indiferencia de alguna cosa ó contraerla á determinada especie. Determinare. \| for. Sentenciar, definir; como DETERMINAR el pleito, la causa etc.

22 DETERMINATIVO. adj. Lo que determina ó resuelve alguna cosa. DefIniens. 
En las ediciones de este periodo se observan asimismo cambios en la marca respecto de la quinta edición, bien porque se añada la especificación Gram., bien porque se omita o se modifique la marca. La mayoría -si no la totalidad- de los cambios constatados ${ }^{23}$ parecen motivados en buena medida por cuestiones tales como la vaguedad que revisten algunas nociones sintácticas -como el concepto de "periodo" antes mencionado-, o la indefinición de los límites entre retórica o poética y gramática, que afecta de forma especial a las nociones de la sintaxis figurada ${ }^{24}$, o las vacilaciones de la Academia respecto al alcance amplio de la gramática $^{25}$-con la inclusión de la Ortografía y la Prosodia - o su limitación a la Sintaxis, que tenía por objeto la combinación de las palabras en tanto que "partes de la oración", y la Analogía, conceptuada como la parte de la gramática que se ocupaba de las clases de palabras "con todos sus accidentes y propiedades" (GRAE 1796: 2).

Así, por ejemplo, colon, definido como parte de un periodo y alusivo, por tanto, a una noción que consideraríamos sintáctica, pierde en la sexta edición la marca Gram., aunque no varía definición:

Parte ó miembro principal del período. Llámase perfecto cuando por sí hace sentido, ó imperfecto cuando el sentido pende de otro miembro del período. También se da este nombre á la puntuación con que se distinguen estos miembros.

Por el contrario, pleonasmo, sin marca en ediciones anteriores y catalogado como "figura de construcción", se adscribe a la gramática y la retórica en 1852; contracción, asimismo sin marca de especialidad en 1817, queda catalogada como gramatical en 1822 sin variar la definición: "Supresion de algunas sílabas ó letras en una ó mas dicciones". Sinéresis, que figuraba como voz de la prosodia pasa a marcarse como Gram. en 1852, igualmente sin modificar la definición: "Figura por la cual se contraen dos sílabas formando una sola".

Cambian de Ret. o Poét. a Gram. las voces ceuma ${ }^{26}$ (en la edición de 1837) y silepsis ${ }^{27}$ (en la de 1852); varía asimismo la adscripción de apócope ${ }^{28}$, cuyo tratamiento deja bien

23 Serían diez, si nos limitamos a simples cambios de marca, sin cambio en la definición.

24 Da cabida a las alteraciones respecto de lo que se considera el "orden lógico". Calero (2007: 91) destaca que la sintaxis figurada todavía forma parte de la GRAE en 1931.

25 Val Álvaro (1992: 30) destacaba ya la "vaguedad" que transmitía Autoridades respecto a las partes de la gramática. Las diferentes ediciones de la gramática académica de los siglos XVIII y XIX evidencian también cierta indefinición de la Academia en torno a esta cuestión, pese a que en la primera mitad del XIX se asuma en teoría la organización cuatripartita basada en las "cuatro unidades básicas del lenguaje” (Gómez Asencio 1981: 40): letras, sílabas, palabras, oraciones. Si en la primera edición de 1771 se adoptaba una estructuración bimembre (Analogía y Sintaxis), en la edición de 1796 se habla de cuatro partes, pero solo se tratan dos, la Analogía y la Sintaxis, porque la Ortografia se presentaba por separado y "por no haber fixado todavía la Academia las reglas de la verdadera pronunciacion de las voces castellanas" (GRAE, 1796: 2) en lo que atañe a la Prosodia. En la gramática de 1854 se habla solo de dos partes, Analogía y Sintaxis; en la edición de 1870 se retoma la fórmula de las cuatro partes. En cuanto a los diccionarios, es de destacar que en las ediciones del periodo que consideramos las definiciones de ortografía no incluyen, a diferencia de las definiciones de prosodia, que sea una parte de la gramática.

26 CEUMA. Gram. única conexión. Se usa cuando un mismo verbo, conservando siempre su significado, forma con diversos nombres varias oraciones y sentencias. Zeugma.

27 SILEPSIS, f. Gram. Figura de la oración, que se comete cuando se suple lo que falta en ella de la parte mas cercana, mudando el género, número, caso ó algún otro accidente; cuando se atiende mas al sentido que á las palabras. Syllepsis.

28 APÓCOPE. Gram. Figura que se comete suprimiendo alguna letra ó sílaba al lin de la palabra; como algún por alguno, gran por grande. Apocope, amputatio. (1837; 1852); s. f. Poét. Figura que se comete cortando la última silaba á las palabras, para que pueda constar la consonancia del verso. Apocope, amputatio. 
patente los límites difusos entre retórica o poética y gramática que antes se han mencionado: si en 1803 se señala, al igual que en 1780, como "figura" y como voz de la gramática, en la edición de 1817 se conceptúa como término de la poética, y así permanecería hasta la edición de 1837, en que volvería a considerarse voz de la gramática.

En la edición de 1822 pierde la marca Gram. la acepción de construir "traducir del latín al castellano", pero no se añade ningún sentido relacionado con la noción sintáctica denotada por construcción; en cambio se mantiene como gramatical inconstruible que, si bien "no parece tener presencia en el texto gramatical académico" (Blanco 2018: 378), se introdujo en la quinta edición ${ }^{29}$ con el sentido "que no se puede construir". En esa misma edición cambia de fam. a Gram. el lema adjetivar cuyo sentido, procedente de Autoridades, ni es deducible de adjetivo ni se usa, en realidad, en las gramáticas de este periodo como término de especialidad ${ }^{30}$ : "Concordar una cosa con otra, como en la gramática el sustantivo con el adjetivo. Concordem efficere".

La tarea de corrección de las marcas no alcanza, sin embargo, a algunas de las "inconsistencias" de la edición de 1817 señaladas por Blanco (2018: 375); así, por ejemplo, sustantivo, un término sin duda relevante en el campo de la Analogía, sigue sin estar marcado como término específico, a diferencia de la otra clase de nombre, es decir, el adjetivo; continúa igualmente sin marca epiceno aunque sí figuran como Gram. los términos alusivos al resto de los géneros: común, femenino, masculino, neutro.

\section{SOBRE CAMBIOS EN LAS DEFINICIONES DEL ÁMBITO DE LA ANALOGÍA}

Del examen de las definiciones asociadas a las categorías léxicas, a sus componentes, "accidentes" y subcategorías, que constituyen el eje de las gramáticas como objeto de la Analogía, se puede concluir que, si bien hay en los diccionarios de este periodo modificaciones de distinto calado, no hay desviaciones respecto de esa línea de inmovilismo gramatical y fidelidad a la propia tradición que anteriormente se ha mencionado.

En algunas definiciones se observan ligeros cambios de redacción, de estilo, superficiales en definitiva. Por ejemplo, si ablativo se definía en 1817 como "el sexto y último caso de las declinaciones de los nombres", ya en la sexta edición retomaría fórmulas anteriores sustituyendo "de los nombres" por "del nombre" 31 , pero no añadiría la restricción "en latín" hasta la edición de 1869; las entradas de adjunto, conjuntivo, que recurrían a la fórmula "lo mismo que" adjetivo/subjuntivo, a partir de 1822 pasan a remitir directamente a adjetivo, subjuntivo; la definición de imperativo incorporaría otros fines ilocutivos diferentes del mandato en la edición de 1869 , pero el único cambio que se introduce en la sexta edición respecto a la definición de 1817 - "Uno de los cuatro modos de cualquier verbo que sirve para mandar"no atañe al concepto sino solo a la fórmula: "Uno de los cuatro modos del verbo llamado asi porque sirve para mandar", aunque ya la GRAE de 1796 (pág. 89) afirmaba que con el imperativo no solo "se manda", también "se exhorta ó se disuade".

29 Blanco (2018: 378) considera extraña esta adición de inconstruible. Indica que aparece como gramatical en el diccionario de Terreros y CORDE lo documenta en dos textos de José Francisco de Isla, "pero nunca con acepción técnica".

30 Sería ya en 1869 cuando se añadirían acepciones más próximas al sentido gramatical de adjetivar: "Gram. Concordar una cosa con otra, como en la gramática el sustantivo con el adjetivo. |Añadir un adjetivo calificativo al nombre sustantivo. |Convertir en adjetivo un sustantivo".

31 Así aparecía en la primera edición del Diccionario usual en 1780 y se mantiene en la cuarta edición de 1803. 
Se introducen asimismo modificaciones en la definición de algunos términos que no parecen guardar relación con cuestiones relevantes en las gramáticas académicas, aunque sí afectan en este caso a los conceptos. Así ocurre, por ejemplo, con incremento, cuya definición como "el aumento de sílabas que tienen los casos sobre las del nominativo", sin más restricción, es sustituida a partir de 1822 por otra sin duda más adecuada para el español: "El aumento de sílabas que tienen en la lengua latina los casos sobre las del nominativo y los verbos sobre las de la segunda persona del presente de indicativo". Raíz presentaba en la quinta edición una definición que seguía la estela de Autoridades y vinculaba el concepto al tema del verbo, de conformidad asimismo con el uso que se hacía de este término en la gramática: "Aquel tiempo y parte del verbo de quien nacen y se forman otros". En la sexta en cambio se reemplaza por otra que no está relacionada con su empleo en los textos gramaticales de la Corporación ${ }^{32}$ y se mantendrá, no obstante, hasta la undécima ${ }^{33}$ edición: "Voz primitiva de una lengua, de la cual se derivan otras voces". A partir de 1822 se modifica también la definición de pasiva para acotarla a "las lenguas que admiten verbos pasivos" pero no cambia el concepto de voz.

Para poner un último ejemplo de cambio que no afecta a conceptos clave, se puede considerar la modificación que experimenta en 1852 la acepción de partícula marcada como Gram., una modificación que quizá cabría considerar como un caso de adición, puesto que a la vaga definición de ediciones anteriores, en tanto que nombre "genérico"34 aplicable a conjunciones, preposiciones, adverbios, interjecciones, se añade, sin señalarse como acepción, el sentido en el que alude a los prefijos incluidos en las gramáticas de este periodo en la categoría preposición:

\begin{tabular}{|l|l|}
\hline \multicolumn{1}{|c|}{1817} & \multicolumn{1}{|c|}{1852} \\
\hline $\begin{array}{l}\text { PARTÍCULA. Gram. Palabra indeclina- } \\
\text { ble de que se usa en la oración. }\end{array}$ & $\begin{array}{l}\text { PARTÍCULA. [...] } \| \text { Gram. Palabra indeclinable de que } \\
\text { se usa en la oración. En sentido menos lato se contrae á } \\
\text { las muy breves que nada significan por sí fuera de la com- } \\
\text { posición de otras, como in en invertir, pre en preceder. }\end{array}$ \\
\hline
\end{tabular}

Si pasamos a considerar los cambios que sí afectan al eje de la gramática -las "partes de la oración" y sus "accidentes"-, se ha de señalar que, desde la edición de 1832 hasta la undécima,

32 Como indica Val Álvaro (1992: 37), aunque la Academia utiliza terminación para referirse a cualquier clase de palabra, reserva raíz para el verbo por entender que se forma "con un tema según los tiempos". Así tanto en la GRAE de 1796 (pág. 107) como en la de 1854 (pág. 54) se dice que "los tiempos simples se forman de una raíz comun, que es el presente de infinitivo de cada verbo".

33 La definición que recoge la undécima edición incluye tanto la perspectiva diacrónica como la sincrónica:

RAÍZ. Gram. Voz primitiva de un idioma, á diferencia de las que de ella se derivan; elemento el más puro y simple de una palabra, ó sea la parte que de ella queda después de quitarle prefijos, subfijos y desinencias ó terminaciones. Cuando en vocablos de una misma familia subsiste invariable uno de los elementos de que se componen, conócese fácilmente la raíz, que no puede ser otra sino este elemento que no varía. Las letras st son, por ejemplo, la raíz de asiSTir, circunSTancia, conSTar, deSTituir, diSTar, eSTar, inSTar, inSTituir, interSTicio, obSTáculo, persiSTir, preSTar, proSTituir, reSTar, reSTituir, subsiSTir, subSTancia, superSTición, etc.

34 En el prólogo de la gramática de 1796 se alude al uso que hace Correas de partícula como "nombre genérico" para esas cuatro categorías (pág. VIII). Val Álvaro (1992: 41) subraya que ya en Autoridades el tratamiento del término revela la huella de uno de dos sistemas de clasificación de las palabras que tenían en mente los académicos al establecer la planta del diccionario. Destaca asimismo Val Álvaro que en Autoridades copulativas y disyuntivas se caracterizan como "conjunción" y como "partícula", de manera que ambos términos parecen ser tomados como “indiferenciados” (1992: 111). 
en la que se vuelve al tratamiento anterior ${ }^{35}$, se simplifica la entrada de pronombre al omitir las clases - las cuatro reconocidas ${ }^{36}$ en la gramática de $1796^{-}$, definidas ahora, al menos las de los posesivos y los relativos ${ }^{37}$, bajo los lemas correspondientes a su denominación. Pero no cambia el concepto acotado por la definición que se basa en la "teoría sustitutiva" mantenida por la Academia desde su primera gramática hasta la reforma gramatical de 1870, que ya daría entrada a otro planteamiento más innovador en consonancia con las propuestas de Bello (Lázaro Mora 1981: 50) y de otros gramáticos seguidores del modelo filosófico ${ }^{38}$; en el Diccionario solo varía mínimamente la formulación para incluir un "algunas veces" con el que se trataba de soslayar el problema que planteaba el uso adjetivo - no sustitutivo- de posesivos y demostrativos ${ }^{39}$ pero que, como afirmaba Gómez Asencio (1981: 175), resulta "indigno de una definición”:

\begin{tabular}{|l|l|}
\hline 1817 & $1832-1869$ \\
\hline PRONOMBRE. Gram. La diccion que se pone & PRONOMBRE. Gram. Parte de la oración que se \\
en lugar del nombre propio ó apelativo para & pone algunas veces en ella en lugar del nombre \\
evitar la repeticion de él. Hay cuatro géneros & para evitar su repetición. Pronomen. \\
de PRONOMBRES, personales, relativos, & \\
posesivos y demostrativos [...] Pronomen. & \\
\hline
\end{tabular}

Los diccionarios de este periodo también incluyen cambios en el tratamiento de las "partes de la oración" que hay que catalogar como "de más alcance" debido a que afectan a los conceptos teóricos reflejados en la definición de algunas categorías; es el caso tanto del artículo como del nombre y el verbo -las dos categorías pilares de la gramática-, o de las nociones asociadas a los "accidentes" de esas clases, como el modo, el género, los casos y la declinación. Ahora bien, como se podrá comprobar, esos cambios no se orientan en la línea de la tímida "puesta al día" de la Gramática de 1854, que sí tendría ya un reflejo en la edición del Diccionario de 1869; tampoco, como se ha venido apuntando, darían entrada a nociones procedentes de otras maneras de enfocar la gramática. En realidad, los cambios o bien responden a una "puesta al día" de los conceptos gramaticales en la línea de la gramática de 1796 y el modelo, heredado de las gramáticas renacentistas, que representa, o bien parecen vinculados a las vacilaciones que deja entrever la trayectoria de la Academia respecto a cuestiones discutidas en las comisiones de gramática, como las relativas al género o a la existencia de la declinación.

Por lo que respecta al artículo, las definiciones que ofrecen los diccionarios de este periodo siguen señalando como miembros de la clase únicamente el definido (el) y sus variantes, tal como hacen las gramáticas académicas en las ediciones de 1771 y 1796 . El indeterminado (un), incorporado a esta "parte de la oración” en la gramática de 1854, solo

35 Incluyendo ahora los pronombres indeterminados.

36 Personales, demostrativos, posesivos y relativos. Rechazaría expresamente la inclusión de los indefinidos o indeterminados (GRAE 1796: 86).

37 Como se dijo anteriormente, no se incluyen sentidos gramaticales para personal y demostrativo.

38 En efecto, GRAE de 1870 acogería ya el planteamiento más "moderno" según el cual el pronombre se debería caracterizar por su función discursiva, por su papel indicador de "las personas que intervienen en el coloquio" (Sarmiento 1979: 85).

39 Así, sobre los posesivos diría la Academia (GRAE 1854: 40) que, en rigor, no son pronombres, "pues con ellos no se suple en ningun caso á los sustantivos, sino verdaderos adjetivos; mas, por derivarse de los pronombres personales, y por respeto á la costumbre, se les conserva dicha denominación". 
se mencionaría en el diccionario a partir de la undécima edición. Pero mientras la caracterización que ofrecen los diccionarios hasta la edición de 1837 se basaba en el valor "señalagéneros", "el de más pura raigambre tradicional” (Gómez Asencio 1981: 159), que utilizaba para la definición del artículo la primera gramática académica ${ }^{40}$, desde 1837 hasta la edición de 1852 el concepto delimitado por la definición sigue a la gramática de $1796^{41}$ : al igual que este texto basa la caracterización del artículo en un valor "determinativo" que puede recordar el enfoque de la gramática filosófica pero que resulta en realidad un concepto vago ${ }^{42}$ que, como antes se indicó, no acaba de definirse ni en la gramática ni en el diccionario:

\begin{tabular}{|l|l|}
\hline \multicolumn{1}{|c|}{1817} & \multicolumn{1}{|c|}{$1837-1852$} \\
\hline ARTÍCULO. Gram. Partícula que sirve para & ARTíCULO. Gram. Parte de la oración que \\
denotar el género de los nombres, y el número & precede al nombre para señalar y determinar \\
de las personas, como el para el masculino, la & la persona, cosa ó acción significada por este. \\
para el femenino, lo para el neutro. Articulus, & Articulus, partícula. \\
particula. & \\
\hline
\end{tabular}

El nombre, concebido, de conformidad con las GRAEs de este periodo ${ }^{43}$, como categoría que abarca a sustantivos y adjetivos, "por el omnímodo poder de la tradición" (Gómez Asencio 1981: 132), mantendría hasta la octava edición un tipo de definición basado en los rasgos formales de género y caso que procedía de Autoridades pero no entroncaba con la caracterización nocional que ofrecían las gramáticas académicas. En la novena y en la décima $^{44}$ en cambio se optaría por delimitar la categoría tomando como base los significados asociados a sustantivos y adjetivos, en la línea, ahora sí, de las gramáticas:

\begin{tabular}{|c|c|}
\hline 1817 & $1843-1852$ \\
\hline $\begin{array}{l}\text { NOMBRE. Gram. La primera parte de la oracion, } \\
\text { que se declina por casos. Tiene generos, y no } \\
\text { significa tiempo, y se divide en sustantivo, que es } \\
\text { el que por si solo puede estar en la oracion, y en } \\
\text { adjetivo, que siempre está aplicado al sustantivo. }\end{array}$ & $\begin{array}{l}\text { NOMBRE. Gram. Una de las principales partes } \\
\text { de la oración, que sirve para designar los objetos } \\
\text { ya sean corpóreos ó abstractos, y las calidades } \\
\text { que se les atribuyen. Cuando se limita á denotar } \\
\text { algunos objetos se llama sustantivo, y cuando } \\
\text { sirve para aplicarles cualidades, se llama adjetivo } \\
{[\ldots]}\end{array}$ \\
\hline
\end{tabular}

Otro tanto cabe decir de la definición de sustantivo, que a partir de la octava edición tomaría como base un criterio nocional ${ }^{45}$ frente a la caracterización de ediciones anteriores basada, como la de Autoridades, en la independencia sintáctica:

40 "El ARTÍCULO es una parte de la oración que sirve para distinguir el género de los nombres" (GRAE 1771: 50). 41 "El artículo es una parte de la oracion, que se junta solo al nombre sustantivo, ó á otra parte que haga veces de nombre, para señalar y determinar la persona, cosa ó accion de que se habla; y por lo mismo se llama definido ó determinado" (GRAE 1796: 9).

42 Difícilmente el concepto de determinación que utiliza la Academia en estos textos podría asociarse con, por ejemplo, la fijación de la extensión.

43 Incluida la edición de 1854.

44 A partir de 1869 el nombre, definido asimismo nocionalmente, aparecerá como una clase primaria de palabras equivalente a sustantivo.

45 Ya utilizado para definir la subclase adjetivo. 


\begin{tabular}{|l|l|}
\hline \multicolumn{1}{|c|}{1817} & \multicolumn{1}{|c|}{$1837-1852$} \\
\hline $\begin{array}{l}\text { SUSTANTIVO. s. m. El nombre que por sí solo } \\
\text { puede estar en la oracion á diferencia del ad- } \\
\text { jetivo. }\end{array}$ & $\begin{array}{l}\text { SUSTANTIVO [...] } \| \mathrm{m} \text {. El nombre que significa } \\
\text { alguna persona, cosa, ó propiedad considerada } \\
\text { en abstracto. }\end{array}$ \\
\hline
\end{tabular}

Si los cambios en el tratamiento de la categoría reflejan una aproximación al enfoque de la propia gramática académica, los que afectan al género, la declinación y los casos -los "accidentes" del nombre- parecen vinculados a la "naturaleza polémica" de las nociones, evidenciada ya en los cambios que experimenta su descripción en diferentes ediciones de la gramática. El tratamiento del género, por ejemplo, pone de manifiesto las oscilaciones de los gramáticos respecto a la caracterización de la categoría a partir del valor "señalagéneros" del artículo, tal como había hecho la GRAE de $1771^{46}$, o a partir de "la terminación" del nombre de conformidad con la GRAE de 1796. Así, la definición de género recogida en la quinta edición toma como base, además del "sexo", la terminación; mantiene ese criterio para la definición del femenino, pero no hace lo mismo con el masculino, que incorpora la concordancia con el artículo como rasgo caracterizador.

La entrada de género que sustituye en 1822 a la anterior elude, en realidad, acotar el concepto; simplemente se menciona como categoría que abarca los distintos géneros reconocidos en la gramática. No obstante, de la definición de femenino, que sigue el criterio de la quinta edición -añadiendo una matización sobre las "excepciones"- y de masculino, ahora sí definido con el mismo criterio, se puede inferir que se adopta nuevamente el concepto de género basado en las terminaciones, como en la gramática de 1796 y no el valor "señalagéneros" del artículo:

\begin{tabular}{|l|l|}
\hline \multicolumn{1}{|c|}{1817} & \multicolumn{1}{|c|}{$1822-1852$} \\
\hline $\begin{array}{l}\text { GÉNERO. Gram. La division de los nombres } \\
\text { segun los diferentes sexos ó terminaciones. } \\
\text { Genus. }\end{array}$ & $\begin{array}{l}\text { GÉNERO. Gram. La división de los nombres } \\
\text { según las diferentes clases de masculinos, } \\
\text { femeninos y neutros. Genus. }\end{array}$ \\
\hline $\begin{array}{l}\text { FEMENINO Gram. El nombre que significa } \\
\text { hembra de cualquier especie, y tambien el que } \\
\text { no significándola se reduce á este género por su } \\
\text { terminación. Femininus. }\end{array}$ & $\begin{array}{l}\text { FEMENINO. [...] \| Gram. El nombre que } \\
\text { significa hembra de cualquiera especie, y también } \\
\text { el que no significándola se reduce á este género } \\
\text { por su terminación, si bien hay en esto varias } \\
\text { excepciones. Femineus. }\end{array}$ \\
\hline $\begin{array}{l}\text { MASCULINO Gram. El nombre que significa } \\
\text { hombre, ó macho de qualquier especie de } \\
\text { animal; y tambien á quien se junta naturalmente } \\
\text { el artículo el; como el papel, el carbon, \&c. } \\
\text { Masculinum genus. }\end{array}$ & $\begin{array}{l}\text { MASCULINO. Gram. El nombre quo significa } \\
\text { varón ó macho de cualquiera especie de animal, y } \\
\text { también el que no siéndolo se reduce á esto género } \\
\text { por su terminación ó por el uso. Masculinus }\end{array}$ \\
\hline
\end{tabular}

Se constatan asimismo algunos cambios en las definiciones asociadas a los casos de la declinación que parecen poner de manifiesto los problemas que presentaba para los gramáticos la aplicación a la gramática española de los conceptos formales, no funcionales,

46 Sostenía que para la determinación del género no necesitábamos la terminación, sino el artículo y los adjetivos (GRAE 1771: 131). 
de declinación ${ }^{47}$ y de caso. La primera gramática académica justificaba la supresión de la declinación y de los casos en la gramática porque la "lengua castellana", a diferencia del latín, se servía de las preposiciones para expresar "el diferente oficio que cada caso tiene en latín" y no admitía "variedad de casos, ó terminaciones en los nombres" (GRAE 1771: 24). La edición de 1796, en cambio, mantenía la declinación del artículo, el nombre y el pronombre, advirtiendo que en nuestra lengua se habían suplido "los casos con preposiciones" (GRAE 1796: XX), un planteamiento acorde con la definición de caso que recoge el Diccionario desde la cuarta edición hasta la décima: "La diferente significación de los nombres por razón de la diversidad de sus terminaciones, ó por las preposiciones con que se juntan; como del hombre, ó para el hombre". Es evidente, no obstante, que los conceptos de caso y de declinación que aún se aplicaban al nombre, el artículo y el pronombre en la Gramática de 1854 no resultaban demasiado claros. Así, si bien en el prólogo de la Gramática de 1796 se hablaba de la "declinación" para esas tres categorías, se consideran también "declinables" 48 , por variar sus terminaciones, el verbo y el participio, aunque advierta que la declinación en los verbos "se llama conjugación" (GRAE 1796: 6); habla asimismo de "caso" como concepto aplicable a todas las partes declinables "á excepción del verbo" (GRAE 1796: 6), pero no lo aplica al participio pese a incluirlo entre las "partes declinables" de la oración. En cuanto a la GRAE de 1854, si bien mantiene la declinación y los casos para el nombre y el artículo, reconoce que solo los pronombres personales "varían de forma según los casos" (GRAE 1854: 2).

No es, pues, extraño que también resulte algo confuso el tratamiento que dan los diccionarios de este periodo a los casos que conforman la declinación. En la quinta edición todos los casos se caracterizan por "su lugar" en el paradigma de la declinación del nombre - primer caso, segundo caso, etc.- y ocasionalmente por su significación. Pero a partir de la séptima se mezclan las definiciones que limitan el concepto de "caso" al latín o al latín y el griego con las que no establecen ninguna restricción. Así en los diccionarios de 1832 a 1852 el vocativo se refiere al latín, el nominativo al latín y al griego, pero en el resto de los casos no se incluyen referencias que los circunscriban a una determinada lengua:

\begin{tabular}{|l|l|}
\hline & \multicolumn{1}{|c|}{$1832-1852$} \\
\hline NOMINATIVO & $\begin{array}{l}\text { Gram. En griego y en latín el primer caso de los seis por donde se declinael } \\
\text { nombre. Nominativus, reclus nominandi casus. }\end{array}$ \\
\hline GENITIVO & Gram. El segundo caso de la declinación de los nombres. Genitivus. \\
\hline DATIVO & Gram. El tercer caso del nombre declinable. Dandi casus, tertius casu. \\
\hline ACUSATIVO & Gram. El cuarto caso en la declinación de los nombres. Accusativus casus. \\
\hline VOCATIVO & $\begin{array}{l}\text { Gram. En la lengua latina el quinto caso de la declinación de los nombres, en el } \\
\text { cual se pone la persona con quien hablamos. Vocativus. }\end{array}$ \\
\hline ABLATIVO & $\begin{array}{l}\text { Gram. El sexto y último caso de las declinaciones del nombre. Ablalivus, sextus } \\
\text { casus. [...] }\end{array}$ \\
\hline
\end{tabular}

47 Como señala Hernando García-Cervigón (2006: 124) se trataba de un “viejo debate” planteado ya en 1740 con vistas a elaborar la primera gramática.

48 Hernando García-Cervigón (2006: 120) llama la atención sobre el hecho de que en la GRAE de 1854 aún alternan los términos declinable, indeclinable, con los más modernos variable e invariable. 
La concepción del ablativo absoluto resulta vacilante. En la quinta edición se limitaba a la lengua latina; en la sexta desaparecería; pero el Diccionario de 1852 lo incorpora de nuevo retomando un concepto más antiguo, acorde con la gramática, que habla de "gerundios" y "participios" que se usan como "absolutos" y son "ablativos" "que penden de una preposición callada” (GRAE 1796: 229):

\begin{tabular}{|l|l|}
\hline \multicolumn{1}{|c|}{1817} & \multicolumn{1}{|c|}{1852} \\
\hline $\begin{array}{l}\text { ABLATIVO ABSOLUTO. Gram. En el idioma latino } \\
\text { aquel que equivale á una proposicion incidente, y sirve } \\
\text { para enunciar una circunstancia de tiempo, instrumento, } \\
\text { causa \&c. Ablativus absolutus. }\end{array}$ & $\begin{array}{l}\text { ABLATIVO [...] } \| \text { ABSOLUTO. Llaman } \\
\text { así los gramáticos al que ni rige ni es } \\
\text { regido. }\end{array}$ \\
\hline
\end{tabular}

Ya en la edición de 1869 se agregaría al acusativo y al ablativo la limitación a la lengua latina, pero habrá que esperar al Diccionario de 1884 para encontrar definiciones de los casos basadas en el papel desempeñado por las unidades nominales en la oración; es decir, en la función, ya incorporada en la GRAE de $1854^{49}$. Así, por ejemplo, la duodécima edición ofrece del nominativo la siguiente definición: "Primero de los casos de la declinación. Designa el sujeto ó agente de la significación del verbo y no lleva preposición".

Por lo que respecta a las definiciones de declinación y de caso, al igual que las de otros términos relacionados como declinar, indeclinable, declinable, se mantendrían sin cambios en los diccionarios de este periodo, fieles al planteamiento de la GRAE de 1796. Así, tanto en el DRAE de 1817 como en el de 1852 se define caso como "la diferente significacion de los nombres en razón de la diversidad de sus terminaciones, ó por las preposiciones con que se juntan", y la declinación como la "variación que en los nombres declinables tienen los casos oblicuos respecto del recto". Sería nuevamente la undécima edición de 1869 la que incorporaría cambios en estas nociones acordes con el supuesto -ya asumido por la Gramática en su quinta edición (GRAE 1854: 2)- de que solo los pronombres, y no los adjetivos o los nombres, varían su significado por la terminación y que, por tanto, para estas dos categorías no existe declinación entendida como variación de la terminación.

El cambio que experimenta el tratamiento del verbo refleja una pauta similar a la comentada para el nombre y el sustantivo. Ciñéndonos a la definición de la categoría y dejando aparte las modificaciones que afectan a las clases incluidas bajo el lema verbo ${ }^{50}$, se ha de destacar que los diccionarios anteriores a 1852 ofrecen, al igual que Autoridades, una carac-

49 Del nominativo, por ejemplo, se dice "que gramaticalmente se llama también sujeto y agente" y con él "se designa el móvil de la acción, pasión \&c del verbo, conduciéndole á los modos y tiempos convenientes"; del acusativo afirma asimismo que "se entiende la persona ó cosa que son objeto ó término directo del verbo, cuando lo tiene" (GRAE 1854: 4).

50 También se modifican las clases que se incluyen en la entrada. En la edición de 1817 figuran deponentes, pasivos, neutros, reflexivos y recíprocos. La clasificación que ofrece la décima edición da cabida a otras clases consideradas en la gramática: activo, auxiliar, defectivo, impersonal, irregular, deponente, neutro, reflexivo, reciproco, sustantivo, regular. Se incluye asimismo pasivo aunque ni la GRAE de 1771 ni la de 1796 contemplaran, como subraya Gómez Asencio (1985: 99), la clase de los verbos pasivos pese a incluir en la definición del verbo la expresión de "la pasión". Siguen faltando, no obstante, algunas clases que sí figuran en la gramática como compuesto, simple, of frecuentativo, que se incluye como lema pero no como subclase. Más completa sería en cualquier caso la clasificación que ofrecería la undécima edición del diccionario: activo, auxiliar, compuesto, defectivo, deponente, frecuentativo, impersonal, incoativo, intransitivo, irregular, pasivo, reciproco, reflejo, reflexivo, regular, simple, sustantivo, transitivo. 
terización "morfológica”, "formal”, que, según Gómez Asencio, "había sido base de algunas definiciones clásicas" o "renacentistas" (1981:186), pero ya resultaba extraña, salvo que se combinase con otro tipo de rasgos, en las gramáticas del periodo que nos ocupa. El diccionario de 1852 presenta, en cambio, el tipo definición que adopta la $G R A E$ de $1796^{51}$; esto es, una definición nocional, "acumulativa" -en cuanto que pretende dar cabida a las subclases semánticas de verbos--, combinada con rasgos morfológicos, que de conformidad asimismo con Gómez Asencio (1981: 188 y sigs.) es propia de los gramáticos más tradicionales en la primera mitad del XIX:

\begin{tabular}{|l|l|}
\hline \multicolumn{1}{|c|}{1817} & \multicolumn{1}{|c|}{1852} \\
\hline $\begin{array}{l}\text { VERBO. Gram. Una de las partes } \\
\text { de la oración que se conjuga por } \\
\text { modos y tiempos. Verbum.[...] }\end{array}$ & $\begin{array}{l}\text { VERBO \| Gram. Aquella parte de la oración que expresa la } \\
\text { acción, pasión ó estado de una persona ó cosa, y que se conjuga } \\
\text { por modos y tiempos. Verbum. [...] }\end{array}$ \\
\hline
\end{tabular}

Algo similar puede decirse respecto al tratamiento del modo, el único de los "accidentes" del verbo que ve modificada su definición en los diccionarios de este periodo, mientras que se mantienen sin cambios las correspondientes a tiempo ${ }^{52}$ y a voz; si hasta la sexta edición la categoría modo se delimitaba, al igual que en Autoridades, utilizando los conceptos de "tiempo" y "afecto", la definición que ofrece el DRAE a partir de 1832 se sitúa más en la línea de la GRAE que de Autoridades; no incluye la referencia al tiempo y adopta una perspectiva semántica que combina los valores asociados a los diferentes modos:

\begin{tabular}{|l|l|}
\hline 1817 & \multicolumn{1}{|c|}{$1832-1852$} \\
\hline $\begin{array}{l}\text { MODO. Gram. La diferencia de conju- } \\
\text { garse los verbos para explicar la diversi- } \\
\text { dad de tiempos ó afectos. Modus. }\end{array}$ & $\begin{array}{l}\text { MODO. Gram. La diferencia de conjugarse los verbos } \\
\text { según la acción se enuncia, se manda, se desea, se } \\
\text { considera subordinada á alguna circunstancia ó se toma } \\
\text { absolutamente. }\end{array}$ \\
\hline
\end{tabular}

No cambian, sin embargo, los conceptos vinculados a los cuatro modos reconocidos en las gramáticas; así el infinitivo se presenta en la décima edición igual que en la quinta, como modo del verbo "que no denota tiempo determinado ni número ni persona". De indicativo se sigue proporcionando una definición vaga, basada en la etimología del término, como la que ofrecía la gramática ${ }^{53}$ : "El primer modo de cada verbo que indica ó demuestra sencillamente las cosas; como yo SOY, tú AMAS etc.”. Se mantiene asimismo la definición de subjuntivo, introducida en el suplemento de la quinta edición, que utilizaba como rasgo caracterizador, de conformidad con la gramática de 1796, la subordinación: "Modo del verbo que necesita otro verbo antecedente expreso ó suplido, á que se junta para tener entera y completa su significación”. En cuanto al imperativo, cambiaría la fórmula definitoria, como ya se indicó, pero no se modificaría el concepto asociado a la definición, más próximo a Autoridades que a la GRAE.

51 "Verbo es una parte de la oración que significa la existencia, accion ú pasion de las personas ó cosas, con varias terminaciones de modos, tiempos, números y personas" (GRAE 1796: 87).

52 Según Quilis Merín (2010: 159), el tratamiento del tiempo verbal se mantiene inalterado en la microestructura de todos los diccionarios académicos desde Autoridades hasta 1869.

53 "Modo indicativo es el que indica ó manifiesta directa y absolutamente la existencia o accion de las personas ó cosas, como: Yo soy, tú lees, aquel escribe, cesa el frio, crece la yerba, brotan los árboles" (GRAE 1796: 96). 
Las definiciones asociadas al resto de las "partes de la oración" no experimentan variaciones en los diccionarios de este periodo. Queda igual la conjunción, definida como "parte de la oración que sirve para juntar, atar ó trabar las palabras y oraciones unas con otras", de conformidad con la "fórmula tradicional" (Martín Gallego 2016: 116, Gómez Asencio 1981: 260) adoptada por la $G R A E$ de 1796, que había extendido a las oraciones la labor conexiva atribuida a las conjunciones ${ }^{54}$. Tampoco se alteran las clases de conjunciones incluidas en los diccionarios, a pesar de que las clases consideradas no se correspondían con las que planteaba la Academia en las gramáticas. Se sigue incluyendo dubitativo como término alusivo a una clase de conjunción, pero ni la GRAE de $1796 \mathrm{ni}$ la de 1854 hablan de este tipo de conjunción; las gramáticas sí mencionan, sin embargo, conjunciones comparativas, condicionales, continuativas, causales, finales, que no tienen cabida en los diccionarios en sus acepciones gramaticales referidas específicamente a una clase de conjunciones y tampoco se utilizan como denominaciones de "clase" cuando se definen las unidades léxicas catalogables como conjunciones. A la conjunción si, por ejemplo, no se le atribuye en los diccionarios de este periodo un valor condicional; para se categoriza en los diccionarios como preposición que introduce la noción de finalidad, pero no hay referencia a para que como conjunción final; porque, por el contrario, sí se clasifica como "conjunción con que se denota la causa, motivo ó razón de alguna cosa", si bien no se utiliza específicamente la denominación "conjunción causal". Se mantendrían asimismo sin cambios las definiciones de las diferentes clases de conjunciones; no cambian, en efecto, las definiciones de copulativo y de adversativo para las que no se utiliza el hiperónimo "conjunción" sino "partícula"; tampoco se corrige la entrada correspondiente a disyunción, que se sigue definiendo como "partícula que sirve para separar el sentido de una oración, aunque une y liga los términos de ella", una caracterización que no se ajusta a "disyunción" sino en todo caso a disyuntivo o disyuntiva.

Se mantiene igualmente la definición de interjección -"Una de las partes de la oración que sirve para expresar los afectos y movimientos del ánimo"-, la de participio, que a lo largo del siglo XIX las gramáticas académicas seguirían presentando como "parte de la oración" en sintonía con su enfoque "tradicional" ${ }^{55}$ (Calero, 1986: 135): "Parte de la oracion que afirma ó niega como el verbo, y se declina y concierta como el adjetivo".

La caracterización de la categoría preposición no se modificaría hasta la edición de 1884 . Los diccionarios de este periodo la presentan, en la línea de Nebrija y de la Gramática de $1796^{56}$, como una "parte de la oración" que abarca preposiciones y prefijos ${ }^{57}$ y entre cuyos rasgos definitorios figura la "rección":

54 La definición que recoge la GRAE de 1771 es la misma que incluía Autoridades: "Es una palabra que sirve para juntar, atar, ó trabar entre sí las demás partes de la oración” (GRAE 1771: 222).

55 Gómez Asencio (1981: 316) subraya que la GRAE de 1771 apunta un "tímido conato de deslatinización de la gramática" al sostener que el participio "participa" solo del verbo, aunque por "respeto a la tradición" lo mantenga como clase de palabras independiente. En la de 1796, en cambio, vuelve a definirse como una parte de la oración que se llama así "porque participa de nombre y verbo" (GRAE 1796: 211).

56 Como destaca Gómez Asencio (1981: 253), la GRAE de 1771 solo consideraba preposiciones las que pueden utilizarse "separadas". No obstante, la edición de 1796, tras incluir en la clase tanto las que solo significan "en composición" y las que lo hacen también "separadas" afirma que solo deben considerarse verdaderas preposiciones las que pueden usarse separadas (GRAE 1796: 247)

57 Prefijo no se incorporaría al Diccionario hasta 1869. 
Parte indeclinable de la oración que precede á la palabra á quien rige ó determina ${ }^{58}$. Sirve también para la composición ó formación de algunos verbos; como en ANTEPONER, PREDECIR, PROCLAMAR etc.

No se toma como referencia el concepto de "relación" que ya se abría paso en las gramáticas del XIX, incluidas las de la Academia. En efecto, la GRAE de 1854 lo destacaría como rasgo definidor de la preposición, pero ya en la edición de 1796 se decía que las preposiciones se anteponían a las palabras para "conducirlas al verdadero sentido de relacion ó respeto que tienen entre sí las cosas que significan" (GRAE 1796: 246).

Aunque la Gramática de 1796 incluía a los numerales "que significan número y sirven para contar" (GRAE 1796: 49) en la clase de los adjetivos, el adjetivo -aún subclase del nombre y no "parte de la oración"- continúa caracterizándose en los diccionarios de este periodo a partir únicamente del rasgo semántico "calidad" que utilizaba para su definición la Gramática de $1771^{59}$; así, de la cuarta edición a la décima ${ }^{60}$, el adjetivo es para el Diccionario "el nombre que se junta al sustantivo para denotar su calidad, como bueno, blanco".

Tampoco variaría la entrada de adverbio, cuya caracterización, la "más tradicional de todas" las de este periodo según Gómez Asencio (1981: 230), se fundamentaba en la etimología del término, de conformidad con las gramáticas de 1771 y 1796 . Tanto para estas gramáticas ${ }^{61}$ como para el Diccionario hasta la décima edición el adverbio es "una de las partes de la oración, que se junta al verbo para modificar y determinar su significación" porque el nombre adverbio quiere decir "junto al verbo" (GRAE 1771: 187) o "adjunto al verbo, como si dixéramos un adjetivo del verbo" (GRAE 1796: 230). Sería ya la undécima edición de 1869 la que daría cabida a la caracterización "más moderna" que ampliaba a otras categorías su capacidad de modificación ${ }^{62}$.

Igualmente, por citar otros ejemplos, permanecería sin modificaciones en las ediciones de este periodo el tratamiento de las clases de nombres. Se mantienen tanto las clases de sustantivos -aumentativo, diminutivo, colectivo, partitivo, ordinal-y sus definiciones como algunas de las "inconsistencias" que presentaba la quinta edición en el tratamiento de las clases de nombres; así, no solo no incluye el Diccionario una acepción técnica para numeral o para gentilicio, como se mencionó anteriormente; tampoco la hay para cardinal-aunque sí para ordinal-, para primitivo -quizá porque pueda deducirse de su definición como palabra de carácter general- o para patronímico o verbal; existe derivativo pero no derivado como clase de nombre; figura simple referido a nombres y a verbos, pero no se incluirá hasta 1884 una acepción técnica equivalente para compuesto. Se mantendrán asimismo sin cambios los tiempos del verbo - con las "inconsistencias" que atribuía Blanco (2018: 396) al tratamiento

58 Aquí "determina" es equivalente a "rige".

59 "NOMBRE ADJETIVO es el que se junta al sustantivo para denotar su calidad como bueno, malo, blanco, negro" (GRAE 1771: 6).

60 Ya en la edición de 1869 se definiría como "parte de la oracion que se junta á los sustantivos para calificarlos, ó para determinarlos".

61 En la edición de 1854 se reconocía que también podía modificar al adjetivo y a ciertos adverbios (GRAE 1854: $109,114)$.

62 En esta edición de 1869 se definía como "parte de la oracion que sirve para modificar la significacion del verbo, ó de cualquiera otra palabra que tenga un sentido calificativo ó atributivo". 
de los términos alusivos a rasgos aspectuales en la quinta edición ${ }^{63}-$, los grados del adjetivo y un largo etcétera.

Hay, pues, cambios que afectan a las "partes de la oración”, el eje de la gramática, pero no reflejan una revisión general de las entradas pertenecientes a este ámbito, ni, como se ha señalado anteriormente, dan cabida a otras formas de concebir las categorías, ni parece que se orienten en una línea algo más innovadora de la $G R A E$ de 1854. Domina la continuidad, el seguimiento de la propia tradición y las modificaciones - no muchas- que afectan a la concepción misma de las categorías y los rasgos vinculados o bien responden a las vacilaciones en el tratamiento de algunas nociones controvertidas como, según se ha visto, sucede con las definiciones de los "casos" o del concepto de "género", o bien suponen una puesta al día conforme al modelo de gramática de 1796 respecto a definiciones más antiguas, como evidencian, por ejemplo, los cambios que afectan a las definiciones de artículo, de nombre, de sustantivo o de verbo.

\section{EN TORNO A LA DEFINICIÓN DE LAS CATEGORÍAS SINTÁCTICAS}

La continuidad y el respeto a la propia tradición que evidencia el examen de las nociones pertinentes en el ámbito de la Analogía prevalecen igualmente en el tratamiento que dan los diccionarios de este periodo a los conceptos clave del dominio sintáctico; viene a reflejar, por tanto, que para la Academia la sintaxis continuaba siendo una parte de la gramática escasamente desarrollada, concebida aún "en función de la palabra" (Gómez Asencio 1981: 42), y no tomaba en consideración las nociones "más sintácticas" que, por influjo sobre todo de los gramáticos filósofos franceses ${ }^{64}$, se iban introduciendo en otras gramáticas.

Si comenzamos por la definición misma sintaxis, ha de admitirse que en este periodo no permanece inalterada. Hasta la sexta edición, el Diccionario, utilizando la fórmula de Autoridades, acotaría el concepto de la siguiente manera: "Modo de coordinar las oraciones ó el tratado de gramática que enseña los casos que pide cada verbo y las oraciones latinas". Desde 1832 hasta la undécima edición de 1869 pasaría a definirse como "coordinación de las palabras en el discurso". No obstante, según subraya Garrido Vílchez (2008: 264), la diferencia entre ambas definiciones sería solo superficial, puesto que por "coordinar oraciones" no se entiende unir oraciones -la oración no es unidad sintáctica central en la gramáticas académicas de este periodo- mediante una relación sintáctica de coordinación -concepto inexistente en la gramática-, sino "ordenar", "disponer" adecuadamente las "partes de la oración", es decir, las palabras pertenecientes a una determinada categoría. Por tanto "coordinar las oraciones" viene a ser lo mismo que "coordinar las palabras"; ambos tipos de definición se refieren a la colocación, la ordenación, de las palabras en unidades más amplias, de forma coherente con un enfoque de la gramática que se basa en la palabra y cifra el objeto de la sintaxis en "el orden y dependencia que deben tener entre sí las palabras" (GRAE 1796: 314) según las reglas del régimen, la construcción y la concordancia.

63 Los diccionarios dan entrada a perfecto como término gramatical, pero no se asocia ninguna acepción gramatical a imperfecto ni figuraría en los diccionarios de este periodo el término pluscuamperfecto.

64 No en vano, como constata Michael (1970: 66), la relevancia de la oración aparece siempre ligada a la orientación filosófica en la historia de la gramática y su identificación como unidad central, por cumplirse en ella la expresión del pensamiento, hace que toda la gramática se llene de apreciaciones sintácticas. 
El escaso desarrollo de la sintaxis en la gramática tiene su correlato en el tratamiento que dan los diccionarios a las nociones asociadas al régimen, la construcción y la concordancia, los conceptos en que se subsumen en las gramáticas académicas de este periodo todas las conexiones sintácticas. O no se modifican, o son objeto de cambios de escasa importancia y, en cualquier caso, no se apartan del sesgo que les confiere una sintaxis que tiene por objeto las relaciones entre pares de "partes de la oración" o "clases de palabras".

La definición de concordancia ${ }^{65}$-no hay una acepción técnica para concordar- se mantendría invariable desde la tercera edición (1791) del DRAE hasta la undécima (1869), pese a que no resultaba demasiado clara por no recoger al menos, como sí hacía la gramática ${ }^{66}$, en qué aspectos debería haber "conformidad o correspondencia" entre las palabras:

1791-1869

CONCORDANCIA. Gram. La conformidad ó correspondencia de las palabras segun las reglas de la gramática de cada lengua. Verborum in re grammatica concordia.

La acepción gramatical de construcción, término alusivo a una parte de la sintaxis ya en la GRAE de 1796, permanece asimismo intacta desde la primera edición hasta la undécima: "La recta disposición de las partes de la oración entre si". Es, sin duda, una definición poco clarificadora respecto al alcance del concepto, en parte porque aún no quedan suficientemente diferenciadas las nociones de "sintaxis" y de "construcción", inicialmente equivalentes en la gramática; pero también se ha de considerar que, en realidad, es difícil apreciar a qué tipo de relación gramatical se aplica el concepto de "construcción" tanto en la GRAE de 1796 como en todas las del siglo XIX. Para la Academia,

La CONSTRUCCION de las partes de la oracion es otra especie de dependencia que las une no con tanta precisión como el régimen sino con alguna mayor anchura y libertad, para evitar la uniformidad que resultaria, si se guardaran constantemente en el uso las reglas del régimen y concordancia de las palabras"(GRAE 1796: 326-327).

Es, en definitiva, una noción entre retórica y gramatical, que alude a una relación entre "partes de la oración", cuya naturaleza no queda suficientemente diferenciada del régimen y parece entenderse sobre todo como una cuestión de estilo y de orden lineal, del que no resultan necesariamente relaciones sintácticas significativas.

La definición de régimen, la noción central de la sintaxis en las gramáticas académicas del XIX, sí experimentaría cambios en el Diccionario, al igual que regir, como concepto asociado. Aunque solo a partir de la quinta edición se marcaría como Gram., desde la cuarta hasta la novena (1843) el Diccionario daría cabida a un concepto de régimen de sesgo latinizante, inexistente ya en la GRAE de 1771 y acorde con las ideas "más tradicionales" (Gómez Asencio 1981: 61), que utilizaba el concepto de "caso" y limitaba las categorías con capacidad de rección al verbo y la preposición: "La construccion de un verbo con la preposicion y caso ó modo que pide, y de una preposicion con su caso correspondiente".

65 Según Iglesias Bango (2011: 680) es la "subdisciplina de la sintaxis" que menos cambia en la gramática de este siglo.

66 La gramática indicaba que se trataba de hacer comunes los "accidentes" de las partes declinables: artículo, nombre, pronombre, verbo y participio (GRAE 1796: 276). 
Esta definición es además coherente con la acepción de regir que estas mismas ediciones marcan como Gram.: "Pedir un verbo tal ó tal preposicion, ó tal ó tal caso ó modo; ó pedir una preposicion este ó el otro caso". Es de señalar, no obstante, que los diccionarios incluirían también otra acepción más acorde con el tratamiento del régimen en las gramáticas, que no tiene marca técnica pero cuya definición sí remite al ámbito de la gramática: "En los estudios de gramática colocar todas las palabras de un autor en su órden gramatical, y dar razon de lo que es cada una de ellas, y de la construccion que pide".

Frente a ese concepto restrictivo y latinizante de régimen, la décima edición daría entrada a una noción más abarcadora y más congruente tanto con los sentidos asociados a regir como con el uso del concepto en la gramática académica. Así junto a una primera acepción que circunscribe el régimen a una relación del verbo con su objeto, el DRAE de 1852 incluiría en la definición de régimen un segundo sentido más amplio en el que tendrían cabida todas las posibles relaciones de dependencia entre las "partes de la oración":

RÉGIMEN. [...] $\|$ Gram. La relación gramatical que requiere cada verbo respecto del objeto á que se refiere, ya sea con preposición ó sin ella. || La dependencia que según las reglas gramaticales tienen entre sí las partes de la oración.

En definitiva, el Diccionario ha ido adaptando el concepto de régimen a la noción perfilada en la Gramática de 1796 y dominante en las demás ediciones del texto académico en el siglo XIX. Así en la edición de 1852 el régimen ya no se define a la manera de las gramáticas latinas como la determinación de la forma gramatical de un elemento - el que se identifica como regido- por otro elemento que se identifica como regente ${ }^{67}$. No obstante, el concepto asociado a esa nueva definición del diccionario resulta impreciso, como también resultan imprecisos en la gramática la noción de régimen y el concepto de "dependencia" en que se basa. El régimen es en la gramática, en realidad, una relación binaria entre "partes de la oración" a la que se reconducen todas la conexiones sintácticamente relevantes entre palabras; así, por ejemplo, lo que hoy consideraríamos la relación entre sujeto y predicado se reduce en la GRAE a que "el nombre" (no el nominativo o el sujeto) "rige al verbo"; igualmente las relaciones entre el verbo y sus complementos ${ }^{68}$ se resumen en fórmulas del tipo "el verbo rige al nombre" (no al "complemento"), mientras que el vínculo entre oraciones propio de la composición oracional ${ }^{69}$ se ve reducido a que una determinada "parte de la oración" (por ejemplo, "el verbo", "la preposición” o "algunas conjunciones") "rige al verbo", no a una "oración” (GRAE 1796: 289, 291, 293, 312, 322).

67 Según Gómez Asencio (1981: 61) ya en la primera mitad del XIX se halla muy extendida en la gramática española una noción de régimen desembarazada de rasgos estrictamente formales y entendida como la relación que tiene lugar cuando una palabra depende de otra. Calero confirma que entre 1847 y 1920 son ya escasos los autores que "echan mano de implicaciones formales en la caracterización del régimen" (1986: 207) y la mayoría lo entienden como "dependencia, relación, subordinación, trabazón, etc. no formal, sino sintáctica y semántica". 68 Véase Iglesias Bango, 2010.

69 No existe en la gramática académica de este periodo una concepción de la oración que permita apreciar la composición oracional. El vínculo entre oraciones se perfila, al igual que el resto de las relaciones de régimen, como una relación entre pares de palabras pertenecientes a una "parte de la oración"; además, en el tratamiento de la oración, la gramática presta atención ante todo a una serie de rasgos formales - orden de palabras, necesidad de preposición, forma verbal-, pero no tiene en cuenta ni unidades complejas ni aspectos de contenido sintáctico, de orden funcional, resultantes de los vínculos sintácticos establecidos entre las palabras. 
El tratamiento que dan los diccionarios académicos de esta etapa a los términos alusivos a unidades superiores a la palabra -oración, cláusula, proposición, frase, periodo- y a los que se refieren a las funciones sintácticas -sujeto, predicado, complemento- se mantiene en la línea de la fidelidad a la gramática académica, renuente, como se ha dicho, a las innovaciones procedentes de otros modelos de gramática.

Por lo que respecta al término cláusula, las GRAEs no incorporan la distinción que, según Lope Blanch (1979a: 33), se había establecido "desde los comienzos mismos de la gramática española" entre oración, como término alusivo a una unidad formada por un nombre y un verbo ${ }^{70}$, y cláusula: unidad con "sentido completo", que podía estar constituida por una oración, por dos o más oraciones o por una expresión sin verbo. Las gramáticas académicas de este periodo utilizan el término cláusula, pero no proporcionan una definición de la categoría ni se puede inferir de su empleo que establezcan una diferencia entre oración y cláusula. La GRAE de 1796, por ejemplo, usa cláusula para aludir a oraciones compuestas, como "los padres que tienen hijos buenos son dichosos, el reyno donde los hombres viven en paz es feliz" (GRAE 1796: 358), o a unidades con más de un "miembro", como "Un vasallo pródigo se destruye a sí mismo: un Príncipe á sí y a sus vasallos", cuyo "segundo miembro", con elementos "callados", sería "un Príncipe á sí y a sus vasallos" (GRAE 1796: 368). Sin embargo, no se utiliza el término cláusula sino oración para aludir a la oración compuesta "La eloqüencia es una facultad, que domina los ánimos de los oyentes (GRAE 1796: 321) o para referir a un enunciado condicional formado por dos miembros: Si no se tienen bien presentes las reglas de la Sintaxis, pueden cometerse, muchos yerros en el uso de la lengua (GRAE 1796: 338).

En cuanto al término proposición, venía siendo utilizado por la Academia, al igual que por muchos otros gramáticos españoles (Lope Blanch 1979a: 29), como equivalente a oración desde la primera GRAE de 1771. De "Nacemos", por ejemplo, se dice que es una "proposición" en que "se suple: los hombres" (GRAE 1771: 237), de las "proposiciones" se afirma que "sirven para declarar nuestros pensamientos" (GRAE 1796: 346); "En mi vida he oído tal cosa", por poner otro ejemplo, se cataloga en la GRAE de 1854 como una "proposición negativa" (GRAE 1854: 347).

Tampoco el término frase aparece asociado en las gramáticas académicas a un concepto claro que aluda a una unidad sintáctica diferenciada. Antes bien, de su empleo se puede inferir que se usaba, ya como sinónimo de oración, ya como equivalente a proverbio o a locución 71 . Así, por ejemplo, “á sabiendas”, “á tientas” son para la Academia "frases o modos adverbiales" (GRAE 1796: 251; GRAE 1854: 121), pero también se identifican como "frases" oraciones como "Los caudales y hacienda eran grandes" (GRAE 1796: 280; GRAE 1854: 140), "No se sabe aún el resultado" (GRAE 1854: 118) o "Un soldado español no se rinde fácilmente a la fatiga" (GRAE 185: 9).

Si consideramos, por último, el término periodo, ha de señalarse que no se emplea como término técnico en las gramáticas académicas anteriores a $1852^{72}$, si bien, de confor-

70 Según Lope Blanch (1979a: 39), la definición nocional de la oración es en la lingüística española "cronológicamente posterior a la definición formal", es decir, a la que toma como base la existencia de nombre y verbo.

71 Usos asimismo registrados en otras gramáticas españolas del XIX (Calero Vaquera 1986: 223; Lope Blanch 1979a: 42).

72 Ya en la edición de 1854 se menciona a propósito del empleo del "condicional". Recuérdese que en uno de los sentidos que adoptaba periodo venía a denotar un enunciado compuesto por dos miembros prótasis y apódosis, 
midad con Lope Blanch (1979a: 41), ya se había utilizado en algunas gramáticas españolas para designar un conjunto de "oraciones" o "proposiciones" con "sentido completo" (Lope Blanch 1979a: 41), como equivalente a cláusula, o para aludir a una unidad discursiva más amplia, que podía estar formada por "cláusulas" o, de modo más específico, "por dos oraciones principales", denominadas prótasis y apódosis, a las que se subordinaban otras partes secundarias (Lope Blanch 1979b: 6).

Habida cuenta de cómo se empleaban en las gramáticas de la Academia los términos alusivos a unidades sintácticas, no sorprende que en los diccionarios académicos de este periodo esos términos no se apartaran en líneas generales del uso que se hacía de ellos en las GRAES y no acotaran, en consecuencia, nociones claras que permitieran inferir si aludían en realidad a conceptos diferentes.

Proposición, por ejemplo, se caracteriza en todas las ediciones del Diccionario de este periodo como una oración sin más signo distintivo que una difusa brevedad que no permite calibrar qué condiciones ha de cumplir una oración para ser catalogada como "proposición":

\begin{tabular}{|l|l|}
\hline \multicolumn{1}{|c|}{1817} & \multicolumn{1}{|c|}{$1832-1852$} \\
\hline $\begin{array}{l}\text { PROPOSICIÓN Entre los dialécticos es una } \\
\text { oracion breve en que se asienta alguna cosa } \\
\text { verdadera ó falsa. Propositio, enuntiatio. }\end{array}$ & $\begin{array}{l}\text { PROPOSICIÓN. Dial. Oración breve en que se } \\
\text { afirma ó niega alguna cosa. Propositio, enuntiatio. }\end{array}$ \\
\hline
\end{tabular}

No hay ninguna referencia, por ejemplo, al uso del término que había hecho en su gramática Bello ${ }^{73}$, según el cual proposición denotaba una unidad integrada por "sujeto y atributo" (Bello 1981: 149) -esto es, por sujeto y predicado- mientras que oración se empleaba para una unidad de sentido completo que podía estar formada por un "conjunto de proposiciones" o por una sola proposición (Bello 1981: 271).

En cuanto al término frase, si en la cuarta edición del diccionario se definía de una manera un tanto oscura como "la oración que expresa el concepto", la caracterización que recoge la quinta tampoco permite delimitar con claridad en qué consiste una frase: "Cierto modo de ordenar las palabras en el discurso para hacerlo mas elegante". En las siguientes ediciones bajo el lema frase se incluirían varias acepciones que presentaban esta palabra como equivalente a proposición (u oración), a locución, al igual que en las GRAEs, o como término para referir al "estilo" de una lengua o de un autor:

FRASE. f. El conjunto de voces que forma una proposición; y en este sentido se entiende la palabra frase cuando de ella se dice que es correcta ó viciosa, natural ó figurada etc. Phrasis. || Locución enérgica, y por lo común metafórica, con la que se significa mas de lo que se expresa ú otra cosa de lo que indica la letra. Emphatice dictum. || El modo particular con que ordena la dicción y expresa sus pensamientos cada escritor, y aun la índole y aire especial de cada lengua; asi se dice; la FRASE de Cicerón se diferencia mucho de la de Salustio; la FRASE castellana tiene gran afinidad y semejanza con la griega.

Sin embargo, en ninguna de las ediciones del XIX daría cabida el DRAE al concepto de frase como unidad compleja mediadora entre la oración y la palabra que permitiría hablar,

como el "periodo" condicional.

73 También utilizaría el término cláusula, pero solo para referir a las construcciones absolutas. 
tal como hacía Bello, de frase sustantiva, frase adjetiva, frase verbal y frase adverbia $7^{74}, \mathrm{y}$ que, como se indicó anteriormente, resultaría esencial para percibir la estructura jerarquizada de la oración.

Cláusula se definiría desde la primera edición del $D R A E$ hasta la undécima como "el período que contiene cabal sentido para su inteligencia". Se reitera, pues, la definición que incluía Autoridades y que se limita a remitir a periodo de una manera, además, un tanto circular, ya que al menos hasta la séptima edición periodo se caracterizaría asimismo como "la cláusula entera y perfecta de la oración".

Al margen de que resulten difusas las nociones asociadas a estos términos en los diccionarios, es también indicativo de la escasa relevancia gramatical de los conceptos sintácticos el hecho de que ni cláusula, ni frase, ni proposición se marcan como voces de la gramática en las ediciones del Diccionario. Frase no tienen marca. El sentido de proposición se circunscribe inicialmente a "los dialécticos" y se marca como Dial. a partir de 1832. Tampoco periodo se presentaría como término gramatical hasta la octava edición en la que, aparte de marcarse como Gram., se modificaría la definición para dotar al término de un sentido equivalente al de oración compleja, sentido que, de conformidad con Calero (2007: 102), procedería de los gramáticos filósofos: "Conjunto de proposiciones ligadas por conjunciones ó relativos, que en el discurso hacen sentido completo"; sin embargo, pese a identificarse con "periodo", cláusula, además de no ver alterada su definición ${ }^{75}$, seguiría apareciendo sin marca.

En cuanto a oración, parece claro que el término no alude a una unidad que pueda considerarse central en los textos gramaticales académicos del XIX. Un indicio claro del escaso peso que tenía el concepto de "oración” en la gramática de la Academia nos lo proporciona el hecho de que, si bien ya en la la GRAE de 1796 se afirmaba que con las oraciones "explicamos nuestros pensamientos" (GRAE 1796: 2), la gramática no se detenía a definir el concepto de "oración" ni incluiría un capítulo específico sobre las oraciones hasta la edición de 1854, que recogería la teoría de las oraciones "en poco más de cuatro páginas" (Garrido Vílchez 2008: 545). En lo que atañe a los diccionarios de la etapa que nos ocupa, la noción asociada al término oración se seguiría delimitando como en la primera edición del DRAE conforme al molde nocional, presente ya en Autoridades: "La expresión que con una ó muchas palabras como partes suyas hace sentido perfecto". No tomaba, por tanto, como rasgo definidor los componentes necesarios para la existencia de la oración, aunque en la Gramática se diga que "para formar oración" es preciso que haya verbo "callado ó expreso y nominativo" (GRAE 1796: 281). Por el contrario, en el Diccionario se apelaba al "sentido perfecto", equivalente al "concepto cabal" que los textos gramaticales acabarían adoptando como criterio definitorio y cuya naturaleza no acabaría de clarificarse. El único cambio que se observa en este periodo en la entrada oración estriba en que a partir de la octava edición (1837) se omite la clasificación de las

74 En la Gramática de Bello aludía a una unidad sintáctica compuesta por un núcleo (sustantivo, verbo, adjetivo, adverbio) y sus modificadores: "Un sustantivo con las modificaciones que lo especifican o explican forma una frase sustantiva a la que es aplicable todo lo que se dice del sustantivo; de la misma manera un verbo con sus respectivas modificaciones forma una frase verbal; un adjetivo con las suyas una frase adjetiva; y un adverbio una frase adverbial." (Bello 1981: 164).

75 Como afirma Val Álvaro (1992: 121), aunque se apoye en la noción asociada a periodo, la definición de cláusula "no excluye la interpretación restrictiva, referida a una entidad simple, de composición y sentido íntegros". 
oraciones basada en la voz, las personas y los términos aparentemente esenciales ${ }^{76}$ que incluían las ediciones anteriores ${ }^{77}$.

Ha de considerarse, por último, que puesto que la sintaxis sigue estando concebida en función de la palabra, que las relaciones entre los elementos de la oración se resumen en relaciones de régimen, construcción y concordancia entre pares de clases de palabras, la oración no podría percibirse en la gramática académica de esta etapa -ni, lógicamente, en las gramáticas que siguen su mismo esquema heredado de la tradición renacentista ${ }^{78}-$ como una estructura articulada, integrada por componentes de diversa complejidad entre los que se establece una red de relaciones significativas. De ahí que, por ejemplo, si bien ya la GRAE de 1854 había utilizado sujeto como equivalente a nominativo, predicado no existiría como concepto pertinente en las gramáticas académicas del XIX y los "complementos" no se mencionarían como componentes de la oración hasta la edición de $1870^{79}$; por lo demás, la referencia a estas categorías funcionales en los textos gramaticales dejaba al descubierto que aún no se percibían como categorías descriptivas realmente operantes.

De forma coherente con el papel que se otorgaba a estas categorías de índole funcional en la Gramática, las ediciones decimonónicas del Diccionario no marcarán predicado como término gramatical. La definición cambia levemente de la quinta a la sexta edición, pero se sigue manteniendo como término de la lógica, vinculado al concepto, también lógico, de "proposición":

\begin{tabular}{|l|l|}
\hline \multicolumn{1}{|c|}{1817} & \multicolumn{1}{|c|}{$1822-1852$} \\
\hline $\begin{array}{l}\text { PREDICADO s. m. Lóg. Lo que se afirma ó nie- } \\
\text { ga del sugeto en la proposicion. Praedicatum. }\end{array}$ & $\begin{array}{l}\text { PREDICADO, m. Lóg. Atributo de una proposi- } \\
\text { ción, lo que se afirma ó niega del sujeto en ella. } \\
\text { Praedicatum, }\end{array}$ \\
\hline
\end{tabular}

También sujeto figuraría exclusivamente con la marca Lóg. hasta la edición de 1869 en que se añadiría la acepción gramatical acorde con el uso que se hacía del término en la GRAE de 1854:

\begin{tabular}{|l|l|}
\hline \multicolumn{1}{|c|}{$1817-1852$} & \multicolumn{1}{|c|}{1869} \\
\hline $\begin{array}{l}\text { SUJETO. Lóg. Aquello de quien se enuncia y } \\
\text { predica alguna cosa. }\end{array}$ & $\begin{array}{l}\text { SUJETO. Lóg. Aquello de quien ó de que se } \\
\text { enuncia alguna cosa. | Gram. El nominativo ó } \\
\text { agente de la oración. }\end{array}$ \\
\hline
\end{tabular}

\footnotetext{
76 En las gramáticas académicas del XIX el tratamiento de la oración responde a un enfoque taxonómico en el que se busca clasificar las oraciones tomando como base rasgos formales. Así, por ejemplo, la clasificación en "primeras" y "segundas" obedece a que aparezcan o no en el esquema oracional los términos considerados esenciales (Calero 2007: 107).

77 Así, al concepto antes citado, las siete primeras ediciones añaden: "Divídenla en primera y segunda de activa y de pasiva, segun la voz del verbo con que se forma, y los casos de nominativo, acusativo ó ablativo de que consta. Cuando solo tiene nominativo y verbo la llaman segunda. Tambien la dividen en personal, impersonal y semiimpersonal".

78 Como se ha indicado anteriormente el cambio de perspectiva de la palabra a la oración que empieza a darse ya a principios del XIX en la gramática española vendría propiciado por los seguidores de los gramáticos filósofos franceses (Calero 2007: 96).

79 Aunque esporádicamente también apareciera el término en la edición de 1854.
} 
En cuanto a la noción de complemento, pese a ser un término introducido en la gramática española de principios del XIX, ni era un concepto relevante en las gramáticas académicas ${ }^{80}$, ni figura en los diccionarios de 1817 y 1852; solo en la edición de 1884 que, según Garrido Vílchez (2008: 293), iniciaría en los diccionarios la maduración "por parte de la Academia de una sintaxis basada en la función", se incorporará una definición que pueda considerarse propia de la gramática junto con una referencia a las clases de complementos (directo, indirecto). Así, al sentido "la perfección, el colmo de alguna cosa", el único asociado a complemento en ediciones anteriores, se añadiría en la duodécima edición la acepción marcada ya como Gram., "Palabra ó frase en que recae ó á que se aplica la acción del verbo".

Queda pues patente que, como planteaba al principio de este apartado, también por lo que atañe a los conceptos del campo sintáctico, en las ediciones del Diccionario desde la de 1817 hasta la de 1852 domina el respeto a la propia tradición y la coherencia entre los planteamientos de las GRAEs y el Diccionario. Son pocos los cambios en las entradas de los términos propios de este ámbito y tanto la asignación de las marcas como la definición de los conceptos sintácticos reflejan el insuficiente desarrollo de esta parte de la gramática que continúa basada en las clases de palabras, así como la desatención de la Academia a las innovaciones que se iban introduciendo en el panorama gramatical español en materia sintáctica.

\section{PARA CONCLUIR}

Para obtener los datos que se han ido comentando en las páginas anteriores, referidos a definiciones de términos gramaticales en los diccionarios académicos de la primera mitad del siglo XIX, se han comparado las definiciones que proporcionaba la quinta edición del $D R A E$ para 177 unidades léxicas relacionadas con el metalenguaje de la gramática con las asociadas a las mismas unidades en las cinco ediciones siguientes, hasta la de 1852. Aunque el examen de esas ediciones constituye la base del trabajo, también, como se habrá podido observar, se han tomado en consideración ocasionalmente otras ediciones anteriores o posteriores al periodo indicado, con el fin de subrayar ya la continuidad ya algunos de los cambios que tal vez podrían haberse realizado.

En la mayoría de los casos las definiciones examinadas corresponden a términos marcados como gramaticales en los diccionarios. Pero, como es lógico, también se ha prestado atención a las definiciones de palabras que, como sustantivo o epiceno, aluden a conceptos gramaticales aunque carezcan de marca, y a las de otras muchas palabras, como desinencia, accidente, antecedente, demostrativo, determinar, sujeto, complemento, predicado, frase, proposición, cláusula, primitivo, numeral, etc., que o no se asocian a conceptos gramaticales en los diccionarios o no se catalogan como gramaticales pese a ser usados como tales en las propias GRAEs o en otros tipos de gramáticas.

Un $75,71 \%$ de las voces examinadas no experimentan cambios ni en la definición ni en las marcas o solo son objeto de modificaciones superficiales, básicamente de estilo, que no afectan a los conceptos acotados. Así ocurre con buena parte de la definición de los términos alusivos a "partes de la oración", a sus "accidentes" y subclases y de los que se refieren a categorías de índole sintáctica.

80 El concepto fue introducido en la gramática española por Jacobo Saqueniza (1828), “el primero y más fiel de los adaptadores" de Gómez Hermosilla (Gómez Asencio 1981: 351). 
En cuanto a los cambios comprobados, en la definición y/o en las marcas, se ha puesto de relieve, en primer lugar, que parte de ellos no atañen a términos que refieran a conceptos relevantes en el "núcleo" - Analogía y Sintaxis- de la gramática.

En segundo lugar, se ha subrayado que las definiciones que sí incorporan cambios en los conceptos asociados a determinadas "partes de la oración”, como sucede con el artículo, el nombre, el verbo o a sus "accidentes"-género, caso, modo, etc.- o sus subclases, o bien responden a los problemas que suscitaban esas nociones entre los gramáticos de la Academia, reflejados ya en las diferencias entre las GRAEs de 1771 y $1796^{81}$, o bien sustituyen definiciones aún basadas en Autoridades pero extrañas ya en los textos gramaticales por otras más acordes con el enfoque "tradicional" de la Gramática de 1796.

Se ha puesto de relieve asimismo que el tratamiento de los términos alusivos a conceptos catalogables como "sintácticos" tampoco experimentan en las ediciones de este periodo cambios "de calado", en línea con el escaso desarrollo de la sintaxis en los textos gramaticales de la Academia, a pesar de las innovaciones que, por influjo de los gramáticos filósofos, se iban produciendo en este ámbito.

Se ha visto, por ejemplo, que sí cambia la definición de régimen -la noción clave de la sintaxis académica de este periodo-, que acaba sustituyendo un concepto ya antiguo de sesgo latinizante por otro más acorde con el utilizado en las GRAE de 1796. Por el contrario, otros términos o solo son objeto de modificaciones superficiales -como sucede, por ejemplo, con la definición misma de sintaxis - o se mantienen sin modificaciones en la definición, a menudo poco clara -como es el caso de construcción, concordancia e incluso oración-, o no solo no introducen cambios importantes en la definición, sino tampoco en las marcas que los excluyen del campo de la gramática, como ocurre, por ejemplo, con sujeto, predicado, proposición, frase, cláusula.

Por lo demás, si, según Blanco (2018: 389), el estudio del léxico de la gramática en la quinta edición "no trasluce una revisión profunda y planificada de esta terminología", tampoco puede decirse que la definición de los términos gramaticales fuese fruto en las cinco ediciones siguientes de una revisión planificada y profunda. Se mantuvieron definiciones que resultaban deficientes incluso respecto de una gramática académica que ya precisaba ser renovada; quedaron sin incorporar términos o sentidos que ya resultaban pertinentes en las gramáticas de la primera mitad del XIX, se conservaron sin corregir definiciones vagas ${ }^{82}$ o mal formuladas, permanecieron sin cambios marcas "gramaticales" no muy justificadas ${ }^{83}$, mientras seguían sin marca acepciones propias de la gramática y persistieron asimismo "inconsistencias", "asimetrías" o "defectividad" en el tratamiento de las clasificaciones de determinadas categorías -nombres, conjunciones, pronombres, verbos, etc.- en relación con las recogidas en los textos gramaticales de la Academia ${ }^{84}$.

En definitiva, la revisión de definiciones de términos gramaticales recogida en los apartados anteriores habrá permitido comprobar, como respuesta a las preguntas planteadas al comienzo de este trabajo, que el tratamiento de estos términos en las cinco ediciones del DRAE

81 También, claro, en las discusiones recogidas en las actas de las comisiones de gramática.

82 Véase, por ejemplo, la de activo - lo que pertenece a la acción del verbo- o de partitivo, "lo que puede partirse o dividirse".

83 Por ejemplo, la que se atribuye a cometer, referido al uso de figuras, o de anómalo, que desaparecerían como voces gramaticales en la undécima edición.

84 Algo que Val Álvaro (1992) atribuía ya a Autoridades 
publicadas desde 1817 hasta 1852 estaría dominado por el continuismo, por la congruencia con la propia tradición académica representada tanto por las ediciones anteriores del Diccionario como por un modelo de gramática que la Academia, no muy dada a innovaciones doctrinales, mantenía vigente desde fines del siglo XVIII a pesar de las muchas novedades que se iban produciendo en la primera mitad del siglo XIX en el panorama gramatical español.

\section{REFERENCIAS BIBLIOGRÁFICAS}

Alvar Esquerra, M. (1983). "Los prólogos del Diccionario académico: nomenclatura específica y microestructura", Revista de Filología Española, LXIII, 3/4, pp. 205-222.

Alvar Ezquerra, M. (1993). "El Diccionario de la Academia en sus prólogos". En Alvar Ezquerra, M. Lexicografia descriptiva. Barcelona: Biblograf, pp. 215-239.

Azorín Fernández, D. (2004). Los diccionarios del español en su perspectiva histórica. Alicante: Universidad de Alicante.

Bello, A. (1981) [1847]. Gramática de la lengua castellana. Edición crítica de Ramón Trujillo. Tenerife: Instituto Universitario de Lingüística Andrés Bello.

Blanco, M.A. (2018). "Las voces de la ortografía y la gramática". En Clavería, G. y M. Freixas (coords.). El diccionario de la Academia en el siglo XIX: la $5^{a}$ edición (1817) al microscopio. Madrid: Arco Libros, pp.371-398.

Bosque, I. (2013). "Las gramáticas de la Academia, el difícil equilibrio entre el análisis y la norma". En Iglesias, C. y J. M. Sánchez Ron (dirs.). La lengua y la palabra. Trescientos años de la Real Academia Española. Madrid: RAE, pp. 237-244.

Calero Vaquera, M. L. (1986). Historia de la gramática española (1847-1920). Madrid: Gredos.

Calero Vaquera, M. L. (2007). "Desarrollo de la sintaxis en la tradición gramatical hispánica". En Dorta, J., C. Corrales y D. Corbella (eds.). Historiografia de la lingüistica en el ámbito hispánico. Fundamentos epistemológicos y metodológicos. Madrid: Arco Libros, pp. 89-118.

Calero Vaquera, M. L. (2008). “Análisis lógico y análisis gramatical en la tradición española: Hacia una (r)evolución de la sintaxis”, Gramma-Temas 3.: España y Portugal en la tradición gramatical, pp. 11-42.

Garrido Vílchez, G. B. (2007). "Jalones decimonónicos en la concepción gramatical de la RAE”, Moenia, 13, pp. 361-384.

Garrido Vílchez, G. B. (2008). Las gramáticas de la real Academia Española: Teoría gramatical, sintaxis y subordinación (18584-1924). Tesis doctoral. Universidad de Salamanca.

$<$ http://www.contrastiva.it/baul_contrastivo/dati/sanvicente/contrastiva/Gram\%C3\%A1tica\%20 espa\%C3\%B1 ola/Garrido\%20Gramaticas\%20RAE.pdf> (01-04-2019)

Garrido Vílchez, G. B. (2009). "Terminología gramatical en la historia de la Real Academia”, Res Diachronicae, vol. 7, pp. 203-21.

Gaviño Rodríguez, V. (2015). Términos gramaticales de la Real Academia Española (TerGraRAE). Madrid: Visor Libros.

Gómez Asencio, J. J. (1981). Gramática y categorías verbales en la tradición española (1771-1847). Salamanca: Ed. Universidad de Salamanca.

Gómez Asencio, J. J. (1985). Subclases de palabras en la tradición española (1771-1847). Salamanca: Universidad de Salamanca.

Gómez Asencio, J. J. (1987). "Naissance et développement de la notion de phrase composée dans les grammaires espagnoles (1771-1851)", Histoire Épistémologie Langage, 9,2, pp. 117-132.

Gómez Asencio, J. J. (2002-2004). "El prólogo como advertencia: el caso de la Gramática de la RAE de 1870", Archivo de filología aragonesa, vol. 59-60.1: 473-490.

Gómez Asencio, J. J. (2008). "El trabajo de la Real Academia Española en el siglo XVIII (y después)", Península. Revista de Estudios Ibéricos, 5, pp. 31-53 
Hernando García-Cervigón, A. (2002). "Tradición e innovación en la doctrina gramatical de la GRAE (1771-1931)", Res Diachronicae, 1, pp. 197-206

Hernando García-Cervigón, A. (2006). "El verbo y las partes invariables de la oración en el Dictamen de la comisión de gramática (1861) de la Real Academia Española”, Revista de Filología Románica, vol. 23, pp. 13-28

Iglesias Bango, M. (2010). "Sobre el origen de los términos complemento/objeto directo, complemento/objeto indirecto en la gramática española". En Assunçao, G., M. Fernandes, M. Loureiro (eds.). Ideias Linguisticas na Peninsula Ibérica (séc. XIV a séc. XIX), Vol. I, Münster: Nodus Publikationen pp. 443-455.

Iglesias Bango, M. (2011). "Alcance y cometido de la Sintaxis en textos gramaticales del siglo XVIII". En Gómez Asencio, J. J. (ed.). El castellano y su codificación gramatical. De 1700 a 1835. Burgos: Instituto Castellano y Leonés de la Lengua, pp. 631-639.

Lázaro Mora, F. (1981). La presencia de Andrés Bello en la Filología española. Salamanca: Universidad de Salamanca.

Lope Blanch, J. M. (1979a). El concepto de oración en la lingüística española. México: UNAM.

Lope Blanch, J. M. (1979b). "La cláusula y el análisis del discurso", Nueva Revista de Filología Hispánica, XXVIII, pp. 1-29.

Martín Gallego, C. (2016). "De la Analogía a la Sintaxis: la conjunción en las gramáticas de la Real Academia Española (1771-1917)", BSEHL, 10, pp. 117-154.

Martínez Linares, M. A. (2006). "El enfoque "atomístico" y la sintaxis en las gramáticas académicas del siglo XIX”, Estudios de Lingüística del Español, 23. <http://elies.rediris.es/elies23/martinez.htm>

Michael, I. (1970). English Grammatical Theories and the Tradition to 1800. Cambridge: Cambridge University Press.

Quilis Merín, M. (2010). “Tradición y novedad en el tratamiento de los tiempos verbales en diccionarios del español en el siglo XIX, BSEHL, 7, pp. 155-172.

Real Academia Española (1771). Gramática de la lengua castellana, ed. Facsímil de R. Sarmiento, 1984. Madrid: Editora Nacional.

Real Academia Española (1780). Diccionario de la lengua castellana. Madrid: Imprenta de D. Joaquín Ibarra. file:///G:/DICCIONARIOS\%20RAE/DICCIONARIOS/Diccionario_de_la_lengua_castellana-1780.pdf (01-04-2018).

Real Academia Española (1796). Gramática de la lengua castellana. Madrid: Viuda de Don Joaquín Ibarra

Real Academia Española (1803). Diccionario de la lengua castellana. $4^{\text {a }}$ edición. Madrid: Viuda de Don Joaquín Ibarra.. file://G:/DICCIONARIOS\%20RAE/DICCIONARIOS/Diccionario_de_la lengua_castellana-1803.pdf (03-04-2018).

Real Academia Española (1817). Diccionario de la lengua castellana. $5^{\text {a }}$ edición. Madrid: Imprenta Real. file://G:/DICCIONARIOS\%20RAE/DICCIONARIOS/EDICI\%C3\%93N\%201817.pdf (0104-2018).

Real Academia Española (1822). Diccionario de la lengua castellana. $6^{\text {a }}$ edición. Madrid: Imprenta Nacional. file://G:/DICCIONARIOS\%20RAE/DICCIONARIOS/Edici\%C3\%B3n\%201822.pdf (01-04-2018).

Real Academia Española (1832). Diccionario de la lengua castellana. $7^{\mathrm{a}}$ edición. Madrid: Imprenta Real. file:///G:/DICCIONARIOS\%20RAE/DICCIONARIOS/Edici\%C3\%B3n\%201832.pdf (0104-2018).

Real Academia Española (1837). Diccionario de la lengua castellana. $8^{\mathrm{a}}$ edición. Madrid: Imprenta Nacional. file://G:/DICCIONARIOS\%20RAE/DICCIONARIOS/Diccionario_de_la_lengua_castellana-21837.pdf (03-04-2018).

Real Academia Española (1843). Diccionario de la lengua castellana. $9^{a}$ edición. Madrid: Imprenta de D. Francisco María Fernández. file://G:/DICCIONARIOS\%20RAE/DICCIONARIOS/Diccionario_de_la_lengua_castellana\%201843.pdf (01-04-2018) 
Real Academia Española (1852). Diccionario de la lengua castellana. $10^{\mathrm{a}}$ edición. Madrid: Imprenta Nacional. file://G:/DICCIONARIOS\%20RAE/DICCIONARIOS/Diccionario_de_la_lengua_castellana\%201852.pdf (15-04-2018).

Real Academia Española. 1854. Gramática de la lengua castellana. Madrid: Imprenta Nacional.

Real Academia Española (1869). Diccionario de la lengua castellana. 11 $1^{\mathrm{a}}$ edición. Madrid: Imprenta de Don Manuel Rivadeneyra. file://G:/DICCIONARIOS\%20RAE/DICCIONARIOS/Diccionario_de_la_lengua_castellana-1869.pdf (01-04-2018)

Real Academia Española (1870). Gramática de la lengua castellana. 12a edición. Madrid: Imprenta y estereotipia de M. Rivadeneyra.

Real Academia Española (1884). Diccionario de la lengua castellana. $12^{\mathrm{a}}$ edición. Madrid: Imprenta de D. Gregorio Hernando. file://G:/DICCIONARIOS\%20RAE/DICCIONARIOS/diccionario\%20 1884.pdf (01-04-2018)

Real Academia Española (1931). Gramática de la lengua española. 34a edición. Bilbao, Madrid, Barcelona: Espasa-Calpe.

Real Academia Española (1992). Diccionario de la lengua española. 21 a edición. Madrid: EspasaCalpe.

Rojo, G. (2001). El lugar de la sintaxis en las primeras gramáticas de la Academia. Discurso leído el día 7 de octubre de 2001, en su recepción pública, por el Excmo. Sr. Don Guillermo Rojo y contestación del Excmo. Sr. Don Ignacio Bosque Muñoz. Madrid.

Ruhstaller, S. (2003). "Las obras lexicográficas de la Academia". En Medina Guerra, A.M. (coord.).Lexicografía española. Barcelona: Ariel, pp. 235-261.

Salvá, V. (1835). Gramática de la lengua castellana según ahora se habla. $2^{\mathrm{a}}$ edición. Valencia: Librería de los SS. Mallén y Berard.

Sarmiento, R. (1979). "Filosofía de la Gramática de la Real Academia". Anuario de Letras XVII: 59-96.

Val Álvaro, J. F. (1992). Ideas gramaticales en el “Diccionario de Autoridades”. Madrid: Arco Libros.

\section{APÉNDICE}

\section{UNIDADES LÉXICAS EXAMINADAS EN LAS DIFERENTES EDICIONES DEL DICCIONARIO DESDE LA $5^{\text {a }}$ DE 1817 HASTA LA $10^{\text {a }}$ DE 1852}

Ablativo, ablativo absoluto, accidente, acento, activamente, activo, acusativo, adjetivar, adjetivo, adjunto, adverbial, adverbialmente, adverbio, adversativo, aféresis, afijo, ambiguo, analogía, anomalía, anómalo, antecedente, antítesis, apelativo, apócope, apódosis, aposición, artículo, aspiración, aspirar, aumentativo, cardinal, causal, caso, casos oblicuos, ceuma, cláusula, colectivo, colon, cometer, comparativo, complemento, compuesto, común, concordancia, condicional, conjugación, conjugar, conjunción, conjuntivo, connotativo, construcción, construir, contracción, coordinación, copulativo, corrección, dativo, declinable, declinación, declinar, demostrativo, derivativo, desinencia, determinante, determinar, determinativo, diminutivamente, diminutivo, disyunción, dual, dubitativo, eclipsis, elidir, elipsis, enclítico, epéntesis, epiceno, epiteto, eufonía, femenino, figura, frase, frecuentativo, futuro, género, genitivo, gentilicio, gerundio, grado, gramática, gramatical, gramaticalmente, hipérbaton, idiotismo, imperativo, imperfecto, impersonal, impersonalmente, inciso, incoativo, incremento, inconstruible, indeclinable, indefinido, indicativo, infinitivo, inflexión, interjección, interrogante, interrogativo, intransitivo, 
masculino, metaplasmo, metátesis, modismo, modo, neutro, nombre, nominativo, número, ordinal, optativo, oración, palabra, parte de la oración, participio, partícula, partitivo, pasiva, pasivamente, pasivo, patronímico, perfecto, periodo, persona, personal, pleonasmo, plural, posesivo, positivo, potencial, predicado, preposición, prepositivo, prepositivos, presente, pretérito, pronombre, pronominal, propio, proposición, prótasis, raiz, recíproco, reflexivo, régimen, regir, relativo, silepsis, simple, síncopa, sinéresis, singular, sintaxis, solecismo, subjuntivo, sujeto, superlativo, sustantivo, terminación, terminar, tiempo, transitivo, verbal, verbo, vocativo, voz

\subsection{Unidades que figuran con acepciones marcadas como Gram. en todas o en alguna de las ediciones.}

Ablativo, ablativo absoluto, acento, activamente, activo, acusativo, adjetivar, adjetivo, adjunto, adverbial, adverbialmente, adverbio, adversativo, afijo, ambiguo, analogía, anomalía, anómalo, antitesis, apelativo, apócope, apódosis, aposición, artículo, aspiración, aspirar, aumentativo, caso, casos oblicuos, ceuma, colectivo, colon, cometer, comparativo, común, concordancia, conjugación, conjugar, conjunción, conjuntivo, connotativo, construcción, construir, contracción, copulativo, corrección, dativo, declinable, declinación, declinar, derivativo, determinante, diminutivamente, diminutivo, disyunción, dual, dubitativo, eclipsis, elidir, elipsis, epéntesis, eufonía, femenino, frecuentativo, futuro, género, genitivo, gerundio, grado, hipérbaton, imperativo, impersonal, impersonalmente, inciso, incremento, inconstruible, indeclinable, indicativo, infinitivo, inflexión, interjección, interrogante, interrogativo, intransitivo, masculino, metaplasmo, metátesis, modo, neutro, nombre, nominativo, número, optativo, oración, parte de la oración, participio, partícula, partitivo, pasiva, pasivamente, pasivo, perfecto, periodo, persona, pleonasmo, plural, posesivo, positivo, potencial, preposición, prepositivo, prepositivos, presente, pretérito, pronombre, propio, raiz, recíproco, régimen, regir, relativo, silepsis, simple, síncopa, sinéresis, singular, sintaxis, solecismo, subjuntivo, superlativo, terminación, terminar, tiempo, transitivo, verbal, verbo, vocativo, voz.

\subsection{Unidades sin marca técnica cuya pertenencia al ámbito de la gramática se indica en la definición o se infiere de ella:}

Aféresis, enclítico, epiceno, epíteto, figura, frase, gramática, gramatical, gramaticalmente, idiotismo, modismo, ordinal, palabra, pronominal, sustantivo.

\subsection{Unidades con otra marca de especialidad:}

Desinencia, cláusula, predicado, proposición, prótasis, sujeto.

\subsection{Unidades sin marca técnica y sin acepción específicamente gramatical:}

Accidente, antecedente, cardinal, causal, complemento, compuesto, condicional, coordinación, demostrativo, determinar, determinativo, gentilicio, imperfecto, incoativo, indefinido, patronímico, personal, reflexivo. 